\title{
Searching for an Environmental Effect of Parental Alcoholism on Offspring Alcohol Use Disorder: A Genetically Informed Study of Children of Alcoholics
}

\author{
Wendy S. Slutske \\ University of Missouri-Columbia
}

\author{
Eric Turkheimer, Robert E. Emery, and \\ K. Paige Harden \\ University of Virginia
}

\author{
Brian M. D’Onofrio \\ Indiana University \\ Andrew C. Heath \\ Washington University School of Medicine
}

\author{
Nicholas G. Martin \\ Queensland Institute of Medical Research
}

\begin{abstract}
The children-of-twins design was used to isolate a potentially causal environmental impact of having an alcoholic parent on offspring alcohol use disorder, by an examination of whether the children of alcoholics were at a higher risk for alcohol use disorders than were the children of nonalcoholic parents, even after correlated familial factors were controlled. Participants were 1,224 male and female twins from 836 twin pairs selected from the Australian Twin Registry, 2,334 of the twins' 18-39-year-old offspring, and 983 spouses of the twins. Lifetime histories of Diagnostic and Statistical Manual of Mental Disorders (4th ed.) alcohol use disorders were obtained by structured, psychiatric, telephone interviews conducted individually with each of the family members. Comparisons of the offspring of twins who were discordant for alcoholism indicated that there was no longer a statistically significant difference between the children of alcoholics and the children of nonalcoholics after genetic and family environmental factors correlated with having an alcoholic parent were controlled. The results of this study suggest that the direct causal effect of being exposed to an alcoholic parent on offspring alcohol use disorder is modest at best.
\end{abstract}

Keywords: children of alcoholics, alcoholism, children of twins, multilevel modeling

It has been estimated that approximately 1 in 4 children under the age of 18 in the United States is exposed to alcohol abuse (AA) or alcohol dependence (AD) in the family (Grant, 2000), an estimate that

Wendy S. Slutske, Department of Psychological Sciences and Midwest Alcoholism Research Center, University of Missouri-Columbia; Brian M. D'Onofrio, Department of Psychological and Brain Sciences, Indiana University; Eric Turkheimer, Robert E. Emery, and K. Paige Harden, Department of Psychology, University of Virginia; Andrew C. Heath, Department of Psychiatry and Midwest Alcoholism Research Center, Washington University School of Medicine; Nicholas G. Martin, Genetic Epidemiology Laboratory, Queensland Institute of Medical Research, Queensland, Australia.

This work was supported by National Institutes of Health Grants AA00264, AA011998, AA07535, AA10249, and HD056354, by the National Alliance for Research on Schizophrenia and Depression, and by the William T. Grant Foundation.

Thanks to Dixie Statham for coordinating the data collection for the twins and spouses, to Alison Mackenzie for coordinating the data collection for the offspring of the twins, and to Edison Choe for assisting with the power analyses. We deeply appreciate the continued participation of the twins and their family members.

Correspondence concerning this article should be addressed to Wendy S. Slutske, Department of Psychological Sciences, University of MissouriColumbia, 210 McAlester Hall, Columbia, Missouri 65211. E-mail: slutskew@missouri.edu has led to the suggestion that "the extraordinary number of children in this country who are exposed to AA and AD defines one of today's major public health problems and demands a comprehensive public policy directed toward prevention and intervention" (Grant, 2000, p. 114). The assumption is that exposure to alcoholism in a parent is causally related to the increased risk of adverse outcomes, including the development of alcoholism, ${ }^{1}$ among the children of alcoholics. This causal interpretation is compelling because the home life of children with alcoholic parents is often characterized by inadequate parenting, conflict, disorganization, or hardship (e.g., Ellis, Zucker, \& Fitzgerald, 1997; Grant, 2000; Jacob \& Leonard, 1994; Windle \& Tubman, 1999). However, because exposure to an alcoholic parent is inextricably intertwined with a network of correlated genetic and environmental risk factors (Ellis et al., 1997), it has been a challenge to demonstrate empirically that this is an active ingredient leading to alcohol use disorders in the children of alcoholics. For example, in conventional children-of-alcoholics studies of parents and their biological offspring, exposure to an alcoholic parent is confounded with correlated genetic and family environmental risk factors.

\footnotetext{
${ }^{1}$ There is no formal diagnostic category that corresponds to alcoholism. To be consistent with the literature on children of alcoholics, and for the sake of brevity, we use the term alcoholic to refer to individuals with alcohol-related problems.
} 
There have been only a few genetically informed studies that have examined alcohol use disorders in offspring exposed to an alcoholic parent, while controlling for the genetic risk for alcoholism that is usually correlated with exposure. In adoption studies, this is typically achieved by comparing the rates of alcohol use disorders in offspring who are adopted into the homes of alcoholic parents with those of offspring adopted into the homes of nonalcoholic parents. Such studies have failed to detect an influence of having an alcoholic adoptive parent on alcohol use disorders in the offspring. For example, in the Stockholm Adoption Study, the rates of AA among 862 male adoptees reared by alcoholic parents versus those reared by nonalcoholic parents were $13 \%$ and $18 \%$, respectively, and the rates were $3.7 \%$ and $3.4 \%$, respectively, among 913 female adoptees (Cloninger, Bohman, Sigvardsson, \& von Knorring, 1985). Two of the Iowa adoption studies (Cadoret, O'Gorman, Troughton, \& Heywood, 1985, 1987) have provided the only evidence of significant associations between alcohol problems in the adoptive family (including the parents, siblings, and more distant relatives) and adoptee alcohol problems, but once the analyses were restricted to parental alcohol problems in the adoptive family, the associations were no longer statistically significant. The Danish adoption study (Goodwin, Schulsinger, Moller, Hermansen, Winokur, \& Guze, 1974), with a slightly different research design, also failed to detect an influence of having an alcoholic rearing parent on alcohol use disorders in the offspring. The rate of alcohol use disorders among 20 adoptedaway sons of biological parents with alcoholism (90\% adopted into the homes of nonalcoholic foster parents) was compared with the rate among 30 offspring who remained with the alcoholic biological parent, that is, who were not adopted away. Sons who were raised by the alcoholic birth parent did not have higher rates of alcohol use disorders (20\%) than the sons who were adopted away and raised by (mostly) nonalcoholic foster parents (25\%).

An alternative, genetically informed research design that circumvents some of the shortcomings of the adoption study is the children-of-twins (CoT) study (Gottesman \& Bertelson, 1989; Heath, Kendler, Eaves, \& Markell, 1985; Nance \& Corey, 1976). The concerns about representativeness that plague adoption studies (Cadoret, 1986; Rutter, Pickles, Murray, \& Eaves et al., 2001; Stoolmiller, 1999) are not as relevant to community-based studies of twins and their families. The CoT design can provide a powerful test of the environmental impact of being exposed to an alcoholic parent, while controlling for correlated genetic (and also environmental) factors. The CoT design is based on similar logic to the Danish adoption study - that is, to hold genetic risk constant while varying the environmental risk of being raised by an alcoholic parent. In the CoT design, one can compare the offspring of monozygotic (MZ) twin pairs who are discordant for alcoholism. The nonalcoholic cotwin serves as a control for the alcoholic twin, and the offspring of these nonalcoholic cotwins are analogous to the offspring who are adopted away from their alcoholic biological parents in the Danish adoption study. Higher rates of alcoholism in the offspring who are reared by the alcoholic twins compared with the rates in their cousins who are reared by the nonalcoholic cotwins provide evidence for a possible causal environmental influence of being exposed to an alcoholic parent. The CoT design actually provides a more stringent test of this effect than the adoption study because, in addition to controlling for correlated genetic risk factors (completely, in the case of MZ twin pairs, or partially, in the case of dizygotic [DZ] twin pairs), it also controls for other unmeasured environmental factors correlated with parental alcoholism that twins can have in common-things such as ethnicity, socioeconomic status, religious affiliation, urban residence versus rural residence (Whitfield, Zhu, Heath, \& Martin, 2005), educational attainment, and shared child-rearing practices (i.e., potential environmental confounds). The CoT design, however, does not provide a perfect environmental control; in this design, environmental factors that twins do not necessarily have in common cannot be controlled for. Although the CoT design can get us much closer to isolating a specific, environmental causal effect of parental alcohol use disorder (AUD) than can most other research designs available, there still remain plausible alternate explanations. (Thus, in this article, we often refer to the potential or possible causal influence of parental AUD, and when these qualifiers are left off for the sake of brevity, they are implied.)

Jacob et al. (2003) represents the only CoT study that has examined the intergenerational transmission of AUDs. The participants were 1,213 male twins from the Vietnam Era twin registry, 1,183 of the twins' 12-26-year-old offspring, and 862 mothers of the offspring. Offspring were divided into six different groups on the basis of whether their father had a history of $\mathrm{AD}$ or $\mathrm{AA}$, whether their uncle had a history of AD or AA, and the twin zygosity of the father. Comparisons of the outcomes in the offspring in these six groups provided evidence for a potentially causal environmental influence of having an alcoholic father. For example, lifetime rates of AD and AA among 18-26-year-old offspring were $19 \%$ and $24 \%$, respectively, when the father had a diagnosis of $\mathrm{AD}$ and were lower, $12 \%$ and $15 \%$, respectively, when the father was unaffected but the genetically identical twin of the father (the uncle) had a diagnosis of AD. Prior to this study, the popular belief that alcoholism in a rearing parent had a potentially causal influence on AUD in offspring had consistently evaded empirical support. However, conclusions drawn from this study may need to be tempered in light of the findings of a recent article presenting follow-up analyses of these data. Duncan et al. (2006) found that among the offspring of fathers with a history of AD, exposure to paternal alcohol-related symptomatology before age 13 years was not related to $\mathrm{AD}$ or $\mathrm{AA}$ in the offspring, leading the authors to conclude that "genetic and high-risk environmental factors that are correlated with lifetime paternal alcoholism may be stronger predictors of offspring alcohol use disorder than fathers' problem drinking" (p. 649).

The purpose of the present study was to attempt to replicate the findings of Jacob et al.'s (2003) landmark study by use of the CoT design to isolate a potentially causal environmental consequence of being exposed to an alcoholic parent on the development of AUD in the offspring. The participants were 1,224 male and female individual twins from 836 twin pairs selected from the Australian Twin Registry, 2,334 of the twins' 18-39-year-old offspring, and 983 spouses of the twins. Unlike many other genetically informative investigations, our purpose was not to decompose variation in AUD into genetic and environmental components-this has been well-studied with other research designs and analytic approaches that are much better suited for this (e.g., Heath et al., 1997; Prescott, Aggen, \& Kendler, 1999; True et al., 1996). Although the CoT design is very useful for controlling for genetic and environmental factors that are correlated with having an alcoholic parent, it is not very useful for decomposing the extent to which these confounding factors are genetic or environmental. 
This requires extremely large sample sizes, particularly when the parent-offspring association is not large. The goal of the present study was to examine whether there is an important and possibly causal environmental influence of parental alcoholism on offspring AUD after controlling for unmeasured familial factors, both genetic and environmental, that are correlated with parental alcoholism.

\section{Method}

\section{Participants}

Data collection for this study proceeded in three stages. The twin parents were members of the volunteer Australian National Health and Medical Research Council Twin Registry whose initial involvement in the registry dated back to 1981. Information from a questionnaire completed by the twins in 1988 or $1989(N=$ 6,$327 ; 83 \%$ response rate) and a telephone interview conducted in 1992 or $1993(N=5,889 ; 86 \%$ response rate) was used to select twin pairs for inclusion in this CoT study. Spouses of the twins participated in a telephone interview conducted between 1994 and 1997 ( $N=3,844)$, and the offspring of the twins were interviewed between 1999 and $2002(N=2,554)$.

Twins in this study were selected from the larger sample of 5,889 participants who took part in the structured, psychiatric telephone interview survey (see Heath et al., 1997, or Slutske et al., 1997, for further details about zygosity determination, attrition, and representativeness of this twin sample). All twin pairs with the following characteristics were selected for the CoT study: Either twin reported in the 1988 questionnaire that they had biological children born between 1964 and 1983 and either twin had a history of AD, conduct disorder, major depression (all based on the 1992 interview), or a history of divorce (based on the 1988 questionnaire or the 1992 interview). In addition, a random sample of twin pairs was selected from among the remaining twin pairs with offspring born between 1964 and 1983 and with no history of AD, conduct disorder, major depression, or divorce. Eighty-five percent of the twins who were contacted agreed to allow us to invite their eligible offspring to participate in the study. After excluding those without parental permission, $82 \%$ of the offspring selected agreed to participate and completed the telephone interview. The complete CoT sample included 2,554 offspring from 889 twin pairs, and data from the 1994-1997 interview of the coparent (the spouses of the twins) were available for 2,048 (80\%) of the offspring.

Previously, we reported a median age-of-onset of Diagnostic and Statistical Manual of Mental Disorders (3rd ed., rev; DSM$I I I-R) \mathrm{AD}$ of 18 years in the original sample of male and female twins (men: $M=18.2$ years, $S D=3.0$, range $=10-35$; women: $M=20.9$ years, $S D=6.8$, range $=10-56$; Slutske, Heath, et al., 1998). More recently, using a different method for ascertaining age-of-onset in the National Comorbidity Survey Replication study, Kessler, Berglund, Demler, Jin, \& Walters (2005) estimated that only one quarter of individuals who eventually develop $\mathrm{Di}$ agnostic and Statistical Manual of Mental Disorders (4th ed.; DSM-IV; American Psychological Association, 1994) AD or AA in their lifetime will be affected by age 18 years (AA) or 19 years (AD); one half will be affected by age 21 years (AA) or 23 years (AD) and three quarters will be affected by age 29 years (AA) or 31 years (AD). Although included in previous studies with this sample (e.g., D’Onofrio et al., 2005; Harden, Turkheimer, et al.,
2007; Lynch et al., 2006), 220 offspring who were 14-17 years of age were not included in this study because they had not yet progressed through enough of the age period of risk for the development of AUDs. The final CoT sample for this study included 2,334 offspring (mean age at interview in 1999-2002 = 25.9 years, $S D=5.2$, range $=18-39$ years, range $=18-30$ years for $80 \%$ of the offspring), 1,224 twins from 836 pairs (mean age at interview in $1992-1993=45.9$ years, $S D=7.1$ ), and 983 spouses of the twins who were the biological parents of the offspring (mean age at interview in $1994-1997=48.9$ years, $S D=7.8)$. The 836 twin pairs included $412 \mathrm{MZ}$ (132 male, 280 female) and $424 \mathrm{DZ}$ (73 male-male, 177 female-female, 174 male-female) pairs.

The offspring in this study represented a relatively broad crosssection of the Australian general population of young adults. Fifty percent $(n=1,176)$ of the offspring were female. Twenty-eight percent of the offspring were currently married, and $68 \%$ had never married (22\% of the never married were currently in de facto marriages). Sixty percent of the offspring were employed full-time, $28 \%$ were employed part-time, $26 \%$ were students, $16 \%$ were homemakers, and $4.5 \%$ were unemployed (the sum of these percentages exceed 100 because more than one of these occupational categories could be selected). Their yearly gross income ranged from less than AU\$4,999 (U.S.\$2,489; $10 \%$ ) to AU\$60,000 (US.\$34,200) or more $(9 \%)$, and the median yearly income at time of interview was AU\$25,000AU\$29,999 (U.S.\$14,250-U.S.\$17,099; 11\%). Twenty-eight percent of the offspring described themselves as working class, $68 \%$ as middle class, and $3 \%$ as upper class. Offspring were most likely to report being raised in the Church of England (26\%), in the Roman Catholic Church (23\%), or with no religion (18\%). Five percent of the offspring acknowledged that their religion had formal rules against all alcohol use.

\section{Data Weighting}

Because the samples for this study were selected on the basis of a history of psychiatric disorders and divorce in the twin pairs, a set of sample-propensity data weights were constructed with the procedure outlined in Heath, Madden, and Martin (1998) to obtain unbiased estimates of parameters and their standard errors. The goal of the data weighting was to recapture the characteristics of the original, unselected twin sample and to also remove any other biases due to nonrandom attrition. Sample-propensity weights were constructed by identifying predictors of whether one or both twins from a pair from the larger sample were included in the CoT sample. Predictors of pairwise rather than individualwise inclusion were examined because selection occurred at the twin-pair level. Propensity weights were then constructed with the inverse probability of the inclusion of a twin pair in the CoT sample. The ability of these propensity weights to remove bias introduced by sample selection and nonrandom attrition was tested by comparison of the weighted and unweighted distributions for demographic, substance use, and psychiatric disorders in the smaller selected CoT sample and the larger original unselected twin sample (for more details, see Harden, Turkheimer et al., 2007). Below, we report the unweighted and weighted estimates of the means and prevalence of the AUD phenotypes used in this study.

\section{Measures}

All of the main measures for this study were obtained via telephone interviews with the twins, their spouses, and their offspring. The 
Semi-Structured Assessment for the Genetics of Alcoholism interview (SSAGA; Bucholz, et al., 1994), originally developed for the Collaborative Study on the Genetics of Alcoholism, was modified for use as a telephone interview in Australia (SSAGA-OZ). Interviews were administered by trained, lay interviewers who were blind to the psychiatric status of the other members of the twin families.

$A U D$ in parents and offspring. Slightly different versions of the SSAGA-OZ interview were used for the twins, the spouses of the twins, and the offspring. Of particular relevance for this study is that the interviews of the twins preceded, whereas the interviews of the spouses and offspring were conducted subsequent to, the introduction of the DSM-IV. The AD and AA symptoms from the twins, spouses, and offspring were scored to be consistent across the family members (although this is not required in the CoT design), while also conforming as closely as possible to the $D S M-I V$ criteria. Only two symptoms deviated slightly from the $D S M-I V$ criteria. The AD withdrawal symptom did not include use of a closely related substance to relieve or avoid withdrawal. Similarly, the AA symptom of continued use despite persistent or recurrent social or interpersonal problems caused or exacerbated by alcohol did not include physical fights as a qualifying problem. In both cases, this was because these were not a part of the DSM-III-R (American Psychological Association, 1987) criteria and were not assessed in the twins. Therefore, they were not included in the DSM-IV AD and AA symptoms and diagnoses for the spouses and offspring.

Two different AUD phenotypes were used to characterize the parental generation: a continuous count, ranging from $0-11$, of the lifetime occurrence of the $7 D S M-I V \mathrm{AD}$ and 4 DSM-IV AA symptoms (AUD symptom count) and a lifetime diagnosis of DSM-IV AD. ${ }^{2}$ AUD among the offspring was characterized with the 11 -item AUD symptom count. The choice of AUD phenotypes in the parental and the offspring generations was based on several considerations, including reliability, statistical power, a consideration of how best to characterize AUD in a parent as an environmental agent, and prior research. On the basis of consistent empirical support, experts now agree that AUDs "are best described on a continuum of severity" (Helzer et al., 2006, p. 303). For example, results of latent trait modeling of AUD symptoms suggest that they all are indicators of a single underlying dimension (Kahler \& Strong, 2006; Krueger et al., 2004). Because of the many advantages of a dimensional measure of AUD, the AUD symptom count was used as the outcome in the offspring. However, because it was not clear that the environmental risk associated with having an alcoholic parent was a continuously graded dose-response phenomenon, and to allow for comparisons with previous studies, we also used categorical AD diagnoses as predictors in the parents. The 1 year test-retest reliability (Pearson's $r$ ) of the AUD symptom count among 176 re-interviewed offspring was .67, and the internal consistency reliability (coefficient alpha) in the full sample of offspring was .79. The reliability of lifetime diagnoses of $\mathrm{AD}$ is high and exceeds that of most other psychiatric diagnoses, with test-retest reliabilities (kappa) over intervals of 2 weeks to 15 months ranging from .61 to .76 (for a review of reliability studies, see Slutske, True, et al., 1998). Means and lifetime prevalence of the two AUD phenotypes are presented in Table $1 .^{3}$ As with any general community sample, identified cases of $\mathrm{AD}$ were relatively mild on average, and only a small fraction of those diagnosed with lifetime $D S M-I V \mathrm{AD}$ in this Australian general community sample had ever sought treatment for their alcohol problems (weighted lifetime prevalence of 3.4\%, 3.3\%, and 3.0\% among twins, spouses, and offspring, respectively).

Other parental characteristics. Demographic characteristics, other substance use, and other psychopathology in the twins and spouses were included as covariates in some of the analyses. Educational attainment was measured on a 7-point Likert scale ranging from less than 7 years of schooling (1) to university postgraduate training (7). Each parent's age at the birth of their first child was calculated based on the twins' and their spouses' reports of all their children's birth dates. Church attendance was measured on a 5-point Likert scale ranging from never (1) to more than once a week (5). A history of divorce was based on reports from the parents and their offspring. Two substance use variables were included: ever smoking cigarettes and ever using any illegal drug. Parental histories of externalizing and internalizing psychopathology were indexed by the number of lifetime $D S M-I I I-R$ symptoms of conduct disorder and major depression, respectively. Lifetime history of suicidality was based on a 5-point Likert scale ranging from no thoughts or plans of suicide (1) to a serious suicide attempt (5; Statham et al., 1998).

\footnotetext{
${ }^{2}$ Analyses were also conducted with a categorical variable corresponding to any $D S M-I V$ alcohol use disorder (i.e., meeting the diagnostic criteria for $\mathrm{AD}$ or $\mathrm{AA}$ ). The results of these analyses were very similar to those for the two phenotypes used in this article and the conclusions drawn were the same. The combination of these two diagnoses was judged to be too problematic because it required experiencing either at least three of seven symptoms (for AD) or one of four symptoms (for AA). Thus, some individuals diagnosed had as few as a single symptom, whereas others with one or two symptoms of $\mathrm{AD}$ did not receive a positive diagnosis.

${ }^{3}$ The mean AUD symptom count and the prevalence of lifetime AD diagnoses were significantly higher in the offspring generation than in the parental generation $(p<.0001)$. To investigate the possible reasons underlying this difference, we compared the 231 twins who were between the ages of 30 years and 39 years when they were interviewed in 1992-1993 with the 634 offspring who were also 30-39 years of age when interviewed in 1999-2002. The weighted mean AUD symptom counts $(p=.58)$ and the lifetime prevalence of $\mathrm{AD}(p=.88)$ among the male and female twins versus male and female offspring who were 30-39 years of age when interviewed did not significantly differ from each other (for example, the weighted lifetime prevalence of $\mathrm{AD}$ among the male twins $=24 \%$, among the male offspring $=$ $24 \%, p=97$, among the female twins $=13 \%$, and among the female offspring $=11 \%, p=.85$ ). This suggests that the differences in the means and prevalence of AUD in the parental and offspring generations do not reflect methodological differences in the interviews with the parents and the offspring but instead must be due to age or birth cohort effects. Comparing individuals born in different years but assessed at the same ages is one method that is used in longitudinal studies to unconfound age and birth cohort effects from each other (another method is to compare individuals born in the same year but assessed at different ages). Our results suggest that the differences in the means and prevalence of AUD in the parental and offspring generations are due to age rather than to birth cohort effects. Higher rates of problems among offspring than among parents would characterize all previous intergenerational studies of AUDs. In fact, similar age differences in the lifetime prevalence of $\mathrm{AD}$ are ubiquitous in the epidemiologic literature (see Rice et al., 2003 for a review of this issue). These age differences were especially evident in this study because of the very wide age range of the unweighted, unselected, original parent samples (e.g., twins ages ranged from 27-90 years; Slutske et al., 1997).
} 
Table 1

Mean Number of Lifetime DSM-IV Alcohol Use Disorder Symptoms and Lifetime Prevalence of DSM-IV Alcohol Dependence Among Twins, Spouses, and Offspring in the Original Samples and in the Weighted CoT Samples

\begin{tabular}{|c|c|c|c|c|c|c|}
\hline \multirow[b]{2}{*}{ Participant } & \multicolumn{3}{|c|}{ Unweighted unselected original sample } & \multicolumn{3}{|c|}{ Weighted selected $\mathrm{CoT} \geq 18$ sample } \\
\hline & Estimate & $S E$ & $N$ & Estimate & $S E$ & $N$ \\
\hline \multicolumn{7}{|c|}{ Mean alcohol use disorder symptom count } \\
\hline \multicolumn{7}{|l|}{ Twins } \\
\hline Men & 1.76 & 0.05 & 2,042 & 1.84 & 0.20 & \\
\hline Women & 0.61 & 0.02 & 3,847 & 0.58 & 0.10 & 81 \\
\hline \multicolumn{7}{|l|}{ Spouses } \\
\hline Men & 1.96 & 0.04 & 2,398 & 2.06 & 0.10 & 629 \\
\hline Women & 0.95 & 0.04 & 1,446 & 0.87 & 0.08 & 354 \\
\hline \multicolumn{7}{|l|}{ Offspring } \\
\hline Men & & & & 2.23 & 0.09 & 1,158 \\
\hline Women & & & & 1.56 & 0.10 & 1,176 \\
\hline
\end{tabular}

\begin{tabular}{|c|c|c|c|c|c|c|}
\hline \multicolumn{7}{|l|}{ Twins } \\
\hline Men $(\%)$ & 17.1 & 0.9 & 2,042 & 16.2 & 3.3 & 409 \\
\hline Women (\%) & 5.0 & 0.4 & 3,847 & 6.7 & 3.3 & 815 \\
\hline \multicolumn{7}{|l|}{ Spouses } \\
\hline Men $(\%)$ & 16.5 & 0.8 & 2,398 & 15.2 & 1.8 & 629 \\
\hline Women (\%) & 6.4 & 0.7 & 1,446 & 5.0 & 1.9 & 354 \\
\hline \multicolumn{7}{|l|}{ Offspring } \\
\hline Men $(\%)$ & & & & 32.2 & 2.4 & 1,158 \\
\hline Women (\%) & & & & 22.5 & 3.5 & 1,176 \\
\hline
\end{tabular}

Note. Only offspring $\geq$ age 18 and their parents are included in the CoT samples. The alcohol use disorder symptom count was an 11-item scale including the 7 symptoms of alcohol dependence and the 4 symptoms of alcohol abuse, CoT = children of twins; DSM-IV = Diagnostic and Statistical Manual of Mental Disorders (4th ed.).

\section{Data Analysis}

For all of the analyses, the AUD symptom counts in the twins, spouses, and offspring were rank normalized with a Blom transformation to reduce the skewness of their distributions and then standardized to means of zero and standard deviations of one (data transformations were conducted separately for the twin, spouse, and offspring samples). Data weights were used for all of the analyses, and all of the available data were analyzed by multiple imputation (Little \& Rubin, 1987), to estimate values for missing parental characteristics. Five imputed data sets were generated based on psychiatric histories in twins, spouses, and all offspring in the family, as well as demographic characteristics of twins and spouses. The uncertainty due to the missing values was reflected in the standard errors obtained from the combined analysis of the five imputed data sets.

Two different data analytic approaches were used to examine the influence of parental AUD on offspring AUD: a descriptive between-families comparison of offspring mean AUD symptom counts grouped according to parental and twin pair history of AUD and multilevel modeling of offspring AUD symptom counts with parental and twin pair history of AUD as Level 2 and Level 3 predictors. Both types of analyses were conducted with SAS PROC MIXED software (Littel, Milliken, Stroup, Wolfinger, \& Schabenberger, 2006) to properly take into account the clustering of the observations within nuclear and twin families. Following the recommendations made by the American Psychological Association Task Force on Statistical Inference (Wilkinson \& The Task Force on Statistical Inference, 1999) and based on the important contributions of Cohen (1994), Kline (2004), Loftus (1996), Lykken (1991), and Schmidt (1996), the primary focus of this article is on the estimation of effect sizes and confidence intervals rather than on null hypothesis significance testing.

Between-families means comparisons. In the descriptive between-families comparisons, all of the means were adjusted for the influence of offspring sex, age, age $^{2}$, and spouse AUD (i.e., assortative mating). ${ }^{4}$ The twin-spouse correlations for the 11-item $\operatorname{AUD}(r=.10, \mathrm{SE}=.03, p<.001)$ and 7-item $\mathrm{AD}$ symptom counts $(r=.13, \mathrm{SE}=.03, p<.001)$ were statistically significant but modest. These low correlations are within the range of estimates ( $r \mathrm{~s}=-.21$ to .40$)$ obtained in other published community-based studies in which assortative mating for AUDs were examined (Agrawal et al., 2006; Kendler, Neale, Heath, Kessler, \& Eaves, 1994; Maes et al., 1998; McLeod, 1993).

The descriptive between-family analyses started with a comparison of the mean AUD symptom counts for offspring, divided into two groups on the basis of whether the twin parent was affected or unaffected with an AUD. This is the type of comparison available in a traditional children-of-alcoholics study, and includes the combined influence of the specific causal environmental effect of parental AUD as well as genetic and family environmental factors that are correlated with having an alcoholic parent.

\footnotetext{
${ }^{4}$ Analyses were also conducted without including spouse AUD as a covariate, and the results were nearly identical to the means analyses in which spouse AUD was included as a covariate. The average difference in the estimated means was only .01 in the two sets of analyses.
} 
The offspring were then further divided, on the basis of whether the parent's cotwin was affected or unaffected with an AUD, into the following four groups: concordant unaffected, discordant-parent unaffected, discordant-parent affected, and concordant affected (see Figure 1). These four groups of offspring were then subdivided on the basis of the zygosity of the twin parent. The comparison of primary interest here was between the offspring of discordantparent affected MZ twins and the offspring of discordant-parent unaffected $\mathrm{MZ}$ twins. This comparison provides the most stringent test of a potential causal effect of parental AUD on offspring AUD. This comparison unconfounds the specific effect of parental AUD from correlated familial factors. If the AUD symptom counts among the offspring in the discordant-parent affected group is higher than that observed among the offspring in the discordantparent unaffected group, then a specific effect of parental AUD is implicated. Conversely, if there are equally elevated AUD symptom counts among the offspring in the discordant-parent affected group and the discordant-parent unaffected group, then correlated familial factors are implicated in the association between offspring AUD and parental AUD. Pairwise comparisons of offspring groups were made on the basis of differences between the standardized least-squares means estimated in SAS PROC MIXED, along with the confidence interval associated with this difference in standardized means.

Analyses were conducted with each of the two parental phenotypes: AUD symptom counts and AD diagnoses. For the purposes of these mean comparisons, the AUD symptom counts for the twin parents were split at less than two symptoms (unaffected) and 2 or more symptoms (affected). Because AUD and AD symptom counts are continuously distributed, it is possible that there were discordant twin pairs who were discordant but who differed by only a single symptom because the affected twin met the diagnostic threshold or cut-off and the unaffected twin fell short by a single symptom (e.g., the affected twin had three AD symptoms and the unaffected cotwin had two). If this level of discordance represented a large proportion of the discordant twin pairs, an influence of parental AUD would be difficult to detect. There were 245 discordant twin pairs when discordance was defined as one twin reporting two or more AUD symptoms and the cotwin reporting less than two AUD symptoms, and there were 152 discordant twin pairs when discordance was defined as one twin being diagnosed with $\mathrm{AD}$ and the cotwin not being diagnosed with $\mathrm{AD}$. The mean differences between the twins in the number of AUD or AD symptoms reported among these discordant pairs was, respectively, 3.1 and $3.0 ; 51 \%$ and $66 \%$ differed by 3 or more symptoms, and only $15 \%$ and $13 \%$ of the discordant pairs differed by only a single symptom. Thus, in the majority of discordant pairs, the affected twin experienced substantially higher levels of AUD or AD symptomatology than did the unaffected cotwin.

Within-family multilevel modeling. An alternative, withinfamily, regression-based data analytic approach was also used. Unlike the simpler between-family means comparisons, the regression-based approach provided rigorous hypothesis testing of effects, allowed direct comparisons between cousins from discordant twin pairs, allowed a number of measured parental characteristics to be statistically controlled, and allowed for tests of sex differences. Three-level multilevel models (Raudenbush \& Bryk, 2002; Singer, 1998) were used to account for the complex data structure of 2,334 individual offspring (Level 1) nested within 1,224 nuclear families (Level 2; "sibships") nested within 836 twin families (Level 3; "cousin-ships"). The mean numbers of offspring in each sibship and cousin-ship were $1.9(S D=0.9$, range $=1-6)$ and $2.8(S D=1.6$, range $=1-10)$, respectively. A series of six different multilevel regression models predicting offspring AUD symptom counts from parental and twin pair history of AUD were fit to the data (see Table 2 for a description of the six models; see D'Onofrio et al., 2005, for detailed algebraic information about the models). Two sets of analyses were conducted with either parental AUD symptom counts entered as a continuous predictor or parental $\mathrm{AD}$ diagnoses entered as a dichotomous predictor (coded: $0=$ unaffected, 1 = affected). The potential influence of assortative mating was taken into account in the multilevel models by including either spouse AUD symptom counts or AD diagnoses as Level 2 predictors in Models 2-6 listed in Table 2. In both sets of analyses, AUD of the spouse provided an incremental contribution over and above twin pair AUD to the prediction of offspring AUD.

Four tests were conducted by including additional predictors in Model 2, but because these yielded nonsignificant effects (in both sets of analyses), they were not retained in subsequent models: (1) The interactive effect of twin and spouse AUD in predicting offspring AUD was tested by including their interaction term as a Level 2 predictor, (2) the differential effects of paternal versus maternal AUD

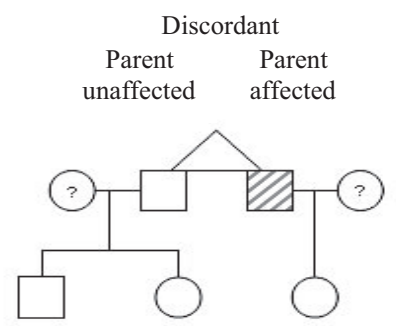

$$
\begin{array}{cc}
\multicolumn{2}{c}{\text { Discordant }} \\
\text { Parent } & \text { Parent } \\
\text { naffected } & \text { affected }
\end{array}
$$
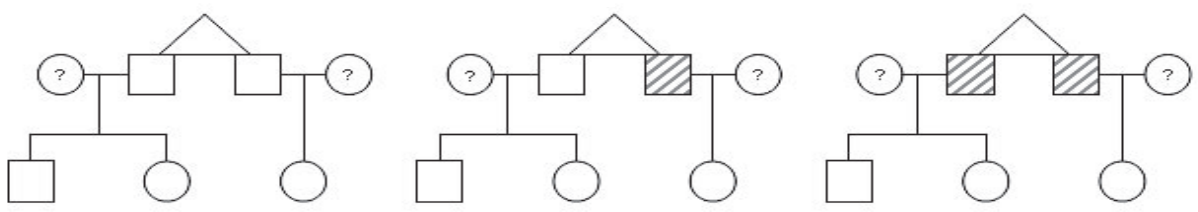

Figure 1. Illustration of the three types of twin families and four different types of nuclear families included in the study. Male participants are represented by boxes, and female participants are represented by circles. Shading represents being affected with an alcohol use disorder. A question mark indicates that the alcohol use disorder diagnostic status of the spouses is to be determined. For illustration, male-male monozygotic twin pairs with three offspring are depicted, but female-female pairs, female-male dizyotic twin pairs, and twin families with anywhere from 1 to 10 children were also included in the study. 
Table 2

Summary of the Multilevel Regression Models Tested

\begin{tabular}{|c|c|c|c|}
\hline Model & Description & Parameters of interest & Explanation and interpretation \\
\hline 1 & $\begin{array}{l}\text { Unconditional } \\
\text { model }\end{array}$ & Random effects & $\begin{array}{l}\text { This is the proportion of variation in offspring AUD explained by } \\
\text { each of the three levels. }\end{array}$ \\
\hline 2 & Phenotypic model & $\begin{array}{l}\text { Twin parent AUD and spouse } \\
\text { parent AUD }\end{array}$ & $\begin{array}{l}\text { This is a traditional analysis of the effect of parental AUD on } \\
\text { offspring AUD, correctly accounting for the levels of clustering } \\
\text { in the data. }\end{array}$ \\
\hline 3 & $\begin{array}{l}\text { Phenotypic model } \\
\text { with covariates }\end{array}$ & $\begin{array}{l}\text { Reductions in twin parent AUD and } \\
\text { spouse parent AUD }\end{array}$ & $\begin{array}{l}\text { This is the extent to which the relation between parental and } \\
\text { offspring AUD is reduced when controlling for demographic } \\
\text { characteristics, other substance use, and other psychopathology } \\
\text { in the twins and spouses. }\end{array}$ \\
\hline \multirow[t]{2}{*}{4} & \multirow[t]{2}{*}{$\begin{array}{l}\text { Cotwin-control } \\
\text { model }\end{array}$} & $\begin{array}{l}\text { Between-twin-family effect of } \\
\text { twins' AUD }\end{array}$ & $\begin{array}{l}\text { This is the effect of the mean AUD score for the twin pair on } \\
\text { offspring AUD. (For a diagnosis, this would equal } 0 \text { for } \\
\text { concordant unaffected twin pairs, } 0.5 \text { for discordant pairs, and } \\
1 \text { for concordant affected pairs.) This affects siblings and } \\
\text { cousins equally. }\end{array}$ \\
\hline & & $\begin{array}{l}\text { Within-twin-family effect of twin's } \\
\text { AUD }\end{array}$ & $\begin{array}{l}\text { This is the difference between an individual twin parent AUD } \\
\text { score and the mean AUD score for the twin pair. This affects } \\
\text { siblings equally, but can differ for cousins. Twins who are } \\
\text { concordant (or have the same number of symptoms) will both } \\
\text { have scores of zero; in discordant pairs, the twin with an AUD } \\
\text { (or with more AUD symptoms) will have a positive score, and } \\
\text { the twin without an AUD (or with fewer symptoms) will have } \\
\text { a negative score. This parameter estimates whether, among the } \\
\text { offspring of discordant twin pairs, the offspring of the twin } \\
\text { with an AUD (or with more AUD symptoms) have more AUD } \\
\text { symptoms than their cousins. This provides a key test of a } \\
\text { potential causal effect of parental AUD on offspring AUD. }\end{array}$ \\
\hline \multirow[t]{2}{*}{5} & \multirow[t]{2}{*}{$\begin{array}{l}\text { Within-zygosity } \\
\text { cotwin-control } \\
\text { model }\end{array}$} & $\begin{array}{l}\text { MZ within-twin-family effect of } \\
\text { twins' AUD }\end{array}$ & $\begin{array}{l}\text { The within-twin-family effect from Model } 4 \text {, in the presence of a } \\
\text { new interaction term, estimates whether, among the offspring } \\
\text { of discordant MZ twin pairs, the offspring of the twin with an } \\
\text { AUD (or more AUD symptoms) have more AUD symptoms } \\
\text { than their cousins. This provides the most stringent test of a } \\
\text { potential causal effect of parental AUD on offspring AUD. }\end{array}$ \\
\hline & & $\begin{array}{l}\text { DZ-MZ within-twin-family effect } \\
\text { of twin's AUD }\end{array}$ & $\begin{array}{l}\text { The interaction of the within-twin-family effect from Model } 4 \\
\text { and twin zygosity (coded } \mathrm{MZ}=0 \text { and } \mathrm{DZ}=1 \text { ), in the } \\
\text { presence of the within-twin-family effect from Model } 4 \text {, } \\
\text { estimates whether the within-twin-family effect differs by } \\
\text { zygosity. This provides a test of whether the familial } \\
\text { confounds explaining the association between parental and } \\
\text { offspring AUD are in part genetic. }\end{array}$ \\
\hline \multirow[t]{2}{*}{6} & \multirow[t]{2}{*}{$\begin{array}{l}\text { Within-zygosity } \\
\text { cotwin-control } \\
\text { model with } \\
\text { covariates }\end{array}$} & $\begin{array}{l}\text { Reduction in the between-twin- } \\
\text { family effect of twins' AUD }\end{array}$ & $\begin{array}{l}\text { The extent to which the between-families association between } \\
\text { parental and offspring AUD is reduced when controlling for } \\
\text { demographic characteristics, other substance use, and other } \\
\text { psychopathology in the twins and spouses. }\end{array}$ \\
\hline & & $\begin{array}{l}\text { Reduction in the MZ within-twin- } \\
\text { family effect of twin's AUD }\end{array}$ & $\begin{array}{l}\text { The extent to which the potential causal effect of parental AUD } \\
\text { on offspring AUD is reduced when controlling for } \\
\text { demographic characteristics, other substance use, and other } \\
\text { psychopathology in the twins and spouses. }\end{array}$ \\
\hline
\end{tabular}

Note. $\quad \mathrm{AUD}=$ alcohol use disorder $\mathrm{MZ}=$ monozygotic; $\mathrm{DZ}=$ dizygotic.

in predicting offspring AUD was examined (after recoding the twin and spouse AUD indicators into paternal and maternal AUD indicators) by including them as separate Level 2 predictors, (3) the differential prediction of AUD in male versus female offspring was tested by including the interaction of parental AUD with offspring sex in the model as a Level 1 predictor, and (4) differences in the prediction of AUD as a function of offspring age was tested by including the interaction of parental AUD with offspring age and/or age ${ }^{2}$ in the model as a Level 1 predictor. Other psychopathology and substance use in the twins and spouses were included (as Level 2 predictors) in Models 3 and 6 to allow for examination of the specificity of the effect of parental AUD and isolation of the effect of parental AUD from other measured risk factors.

\section{Results}

Prior to conducting the more complicated, genetically informed analyses based on offspring AUD symptom counts, we conducted 
standard children-of-alcoholics analyses of the relation between parental $\mathrm{AD}$ diagnosis and offspring $\mathrm{AD}$ diagnosis in order to facilitate comparisons with previous children-of-alcoholics studies. Logistic regression analyses were conducted predicting offspring $\mathrm{AD}$ diagnosis from parental AD diagnosis, accounting for the clustering in the data and using weights to account for the selected nature of the sample. Offspring of parents with a history of AD were significantly more likely to have a history of $\mathrm{AD}$ than were offspring of parents without a history of $\mathrm{AD}$ (odds ratio $=2.7 ; 95 \% \mathrm{CI}: 1.2,6.2), \chi^{2}(1, N$ $=2,334)=5.3, p=.02$. The strength of this association did not differ when the father versus the mother had a history of $\mathrm{AD}, \chi^{2}(1, N=$ $2,334)=0.8, p=.38$, or when the offspring was male or female, $\chi^{2}(1, N=2,334)=0.5, p=.50$.

\section{Offspring Mean AUD Symptom Counts by Parental and Twin Pair History of Alcohol Use Disorder}

Using AUD symptom counts in parents. The first two rows in Table 3 (All twins) show that offspring of parents with two or more lifetime symptoms of AUD had higher scores on the AUD symptom count than did offspring of parents with fewer than two lifetime AUD symptoms $(0.17$ versus -0.06$)$, although the difference in standardized means was small (effect size $d=.24,95 \% \mathrm{CI}$ : 0.12, 0.35). This association was probably not due to a causal effect of parental AUD, because the mean symptom count was the same among the offspring of the affected compared with the offspring of the unaffected twins from $\mathrm{MZ}$ discordant pairs $(0.00$ versus $0.02, d=-.02$, $95 \% \mathrm{CI}$ : $-0.31,0.28$; Rows 4 and 5 in Table 3). ${ }^{5}$

Using $A D$ diagnoses in parents. Offspring of parents with a lifetime diagnosis of AD had higher scores on the AUD symptom count than did offspring of parents without a lifetime diagnosis of $\operatorname{AD}^{6}(0.25$ versus $-0.03, d=.29,95 \%$ CI: $0.12,0.46$; Rows 1 and 2 in Table 4). It was not possible to establish a causal effect of parental AD because the mean symptom count was not substantially higher among the offspring of the affected compared with the offspring of the unaffected twins from the MZ discordant pairs (0.21 versus $0.03, d=.17,95 \% \mathrm{CI}:-0.24,0.58$; Rows 4 and 5 in Table 4). ${ }^{7}$

In both sets of analyses, offspring from twin pairs in which both twins were affected with an AUD were at higher risk for the development of AUD symptoms than were offspring from discordant pairs in which only their parent was affected. This makes sense under the widely held assumption that the etiology of AUD is multifactorial and suggests that families with two affected twins will have a greater loading of the familial risk factors for AUD than will families with only one affected twin. This increased familial loading may be due to either genetic or environmental factors that are shared by twins. In the previous CoT study of Jacob et al. (2003), offspring of parents corresponding to those from rows 5 , 6,9 , and 10 in Table 4 were combined together into a single MZ and $\mathrm{DZ}$ AD group. The results presented in Table 4 suggest that there will be stronger evidence for a potential causal effect of parental AD when this combined group is used in analyses because the difference between this combined parent affected group (i.e., corresponding to rows 5, 6, 9, and 10 combined) and the parent unaffected group will be larger than the difference that is obtained when analyses are limited to the offspring of discordant twin pairs.

In the CoT design, evidence for genetic risk factors contributing to parent-offspring transmission can be demonstrated by observ- ing more pathology in the offspring of the unaffected twins from MZ discordant pairs compared with the offspring of the unaffected twins from DZ discordant pairs. In neither set of between-family analyses was there such evidence of genetic risk contributing to parent-offspring transmission of AUD (Rows 4 and 8 in Table 3: 0.02 versus $0.02, d=0.01,95 \%$ CI: $-0.24,0.25$; Rows 4 and 8 in Table 4: 0.03 versus $0.17, d=-0.15,95 \%$ CI: $-0.49,0.20$ ). However, the very broad confidence intervals around these effect

\footnotetext{
${ }^{5}$ The choice to use a cut-off of 2 or more AUD symptoms in the parents was primarily based on statistical power: $25 \%$ of the twin parents $(n=302)$ were at or above this cut-off. However, this threshold may have been too low to detect an influence of parental AUD. Therefore, the analyses were repeated with higher cut-offs of 3 or more AUD symptoms and 4 or more AUD symptoms; there were two few affected twin parents to examine the effect of higher thresholds of between 5 to 11 AUD symptoms. The results with the higher cut-offs did not differ substantially from the results with a cut-off of 2 AUD symptoms. The effect sizes of the differences in the mean AUD symptom counts of offspring in Row 1 versus Row 2 and Row 4 versus Row 5 were $d=.26$ (95\% CI: $0.13,0.40)$ and $d=.16$ (95\% CI: $-.20,0.53)$, respectively, with a cut-off of 3 AUD symptoms, and the effect sizes were $d=.32$ (95\% CI: $0.14,0.50)$ and $d=.08$ (95\% CI: $-0.38,0.54)$, respectively, with a cut-off of 4 AUD symptoms. Thresholds more extreme than 2 or more AUD symptoms yielded slightly larger differences in the AUD symptom counts of the offspring of affected versus unaffected twins from discordant pairs, but the differences were still small and not statistically significant.

${ }^{6}$ In this CoT sample (and in the larger unselected twin sample), twins with an AUD diagnosis had fewer offspring (they were less likely to have any offspring, although there was no difference in the number of offspring among those who had at least one offspring). Inspection of Tables 3 and 4 reveals that there were fewer offspring among the affected twins than among the unaffected twins from discordant pairs. Among the 245 discordant twin pairs (79 $\mathrm{MZ}+166 \mathrm{DZ}$ ) presented in Table 3, the affected and unaffected twins had 273 and 349 offspring, respectively, and among the 152 discordant twin pairs (48 MZ + $104 \mathrm{DZ})$ in Table 4, the affected and unaffected twins had 110 and 138 offspring, respectively. The analyses for Tables 3 and 4 were rerun, including only those offspring of twins in which both twins from the pair had at least 1 child in this CoT study (67\% of the offspring); this restriction resulted in very similar numbers of offspring among the affected and unaffected twins from discordant pairs. Restricting the analyses to twins with offspring did not change any of the findings in this study. The reduced childbearing among twins with a history of an AUD, compared with twins without a history of an AUD, probably did not affect the results of this study.

${ }^{7}$ Some previous studies have focused on a combined group of MZ and DZ discordant twin pairs either exclusively (e.g., Lynskey et al., 2003; Harden, Lynch, et al., 2007) or in addition to the more conservative comparison of discordant MZ twin pairs presented here (e.g., D'Onofrio et al., 2007; Slutske et al., 2004) in testing potentially causal environmental effects. The rationale is that DZ twins can also serve as a control, especially when there are no differences in the magnitude of the effect observed in discordant MZ twin pairs and DZ twin pairs (e.g., Lynskey et al., 2003) When the data from the offspring of discordant MZ and DZ twin pairs were combined, the mean AUD symptom counts among the offspring of affected twins versus the offspring of unaffected twins from discordant pairs were 0.02 versus 0.02 , respectively $(d=.00,95 \% \mathrm{CI}:-0.17,0.18)$, with the broader definition of AUD in the twins (corresponding to Table 3), and 0.23 versus 0.12 , respectively, $(d=.10,95 \% \mathrm{CI}:-0.13,0.34)$ with the narrower definition of AUD in the twins (corresponding to Table 4). The results of the analyses collapsed across zygosity were very similar to the results obtained when only the offspring of discordant MZ twin pairs were included in the analyses, but the confidence intervals around the estimates were substantially narrower due to the increased sample size.
} 
Table 3

Mean Covariate-Adjusted Offspring Alcohol Use Disorder Symptom Counts by Twin Parent or Twin Pair Alcohol Use Disorder Symptom Counts of Less Than Two (Unaffected) or Two or More (Affected) and Family Type

\begin{tabular}{|c|c|c|c|c|c|c|}
\hline \multirow[b]{2}{*}{ Row } & \multirow{2}{*}{$\begin{array}{l}\text { Alcohol use disorder in twin } \\
\text { parent or twin pair }\end{array}$} & \multicolumn{5}{|c|}{ Offspring alcohol use disorder symptom count } \\
\hline & & $M$ & $95 \% \mathrm{CI}$ & $n$ Offspring & $n$ Twins & $n$ Twin pairs \\
\hline \multicolumn{7}{|c|}{ All twins } \\
\hline 1 & Twin parent unaffected & -0.06 & $-0.12,-0.01$ & 1,778 & 922 & \\
\hline 2 & Twin parent affected & 0.17 & $0.07,0.27$ & 556 & 302 & \\
\hline \multicolumn{7}{|c|}{ Monozygotic twin pairs } \\
\hline 3 & Concordant-unaffected & -0.10 & $-0.18,-0.02$ & 809 & & 271 \\
\hline 4 & Discordant-parent unaffected & 0.02 & $-0.17,0.22$ & 126 & & \multirow{2}{*}{79} \\
\hline 5 & Discordant-parent affected & 0.00 & $-0.23,0.23$ & 86 & & \\
\hline 6 & Concordant-affected & 0.32 & $0.14,0.51$ & 171 & & 62 \\
\hline \multicolumn{7}{|c|}{ Dizygotic twin pairs } \\
\hline 7 & Concordant-unaffected & -0.07 & $-0.16,0.02$ & 620 & & 209 \\
\hline 8 & Discordant-parent unaffected & 0.02 & $-0.13,0.17$ & 223 & & \multirow{2}{*}{166} \\
\hline 9 & Discordant-parent affected & 0.03 & $-0.14,0.19$ & 187 & & \\
\hline 10 & Concordant-affected & 0.41 & $0.19,0.62$ & 113 & & 49 \\
\hline
\end{tabular}

Note. Covariates included were offspring age, age ${ }^{2}$, and sex, and co-parent (spouse) alcohol use disorder. Offspring symptom counts were transformed and standardized to a mean of zero and standard deviation of one. Means were weighted to produce estimates from the entire Australian Twin Registry cohort, and the confidence intervals reflect the clustered nature of the data. The boxes correspond to the discordant twin pairs in the tables. The two rows within each box correspond to either the affected or the unaffected twin from these discordant twin pairs. CI $=$ confidence interval.

size estimates indicate that effect sizes consistent with heritabilities as high as $100 \%$ and $80 \%$ could not be ruled out on the basis of these results. This highlights the low power of this CoT design for detecting genetic effects.

\section{Multilevel Regression Models of the Association Between Parental and Offspring AUD}

Using AUD symptom counts in parents. Table 5 presents the results of fitting the six multilevel regression models predicting offspring AUD symptom counts from AUD symptom counts in the parents. The unconditional model (Model 1) indicated that there was significant variation in offspring AUD attributable to all three levels: the individual offspring, nuclear family, and twin family levels. The proportion of variation accounted for by the nuclear family level $[(0.21 / 0.21)+0.07+0.60]$ can be interpreted as the sibling intraclass correlation for AUD symptoms $(r=.24)$. Similarly, the proportion of variation accounted for by the twin family level $[(0.07 / 0.07)+0.21+0.60]$ can be interpreted as the cousin intraclass correlation for AUD symptoms $(r=.08)$. The remaining $68 \%$ of the variation in offspring AUD was accounted for by influences not shared with siblings or cousins (and also any measurement error).

The phenotypic model (Model 2) is similar to a traditional childrenof-alcoholics study. This model confirmed a small but statistically significant effect of parental AUD on offspring AUD. Each standard deviation in AUD symptoms in the twin or in the spouse was associated with an additional 0.14 standard deviations in AUD symptoms among the offspring. The influence of maternal alcohol problems was slightly larger $(b=.11,95 \%$ CI: $0.07,0.15)$ but not statistically different from paternal alcohol problems $(b=.08,95 \%$ CI: 0.06 , 0.11 ) in predicting offspring AUD. The phenotypic model with covariates (Model 3) indicated that the effect of twin and spouse AUD on offspring AUD was still statistically significant after controlling for demographic characteristics, other substance use, and other psychopathology in the twins and spouses.

The results of fitting the cotwin-control model (Model 4) indicated that there was a statistically significant between-twinfamilies effect of AUD in a twin pair $(b=.18,95 \%$ CI: 0.12 , 0.24); in other words, offspring of parents from twin pairs with a higher mean number of symptoms between the two twins had more AUD symptoms than did unrelated offspring of parents from twin pairs with a lower mean number of symptoms between the two twins. There was not a statistically significant within-twin-family effect $(b=.06,95 \% \mathrm{CI}$ : $-0.02,0.14)$, meaning that offspring whose twin parent had more symptoms did not experience more AUD symptoms than did their cousins whose twin parent had fewer symptoms, and the results of Model 5 indicated that there also was not a statistically significant within-twin-family effect among the offspring of MZ twin pairs $(b=.07,95 \% \mathrm{CI}:-0.07$, 0.21 , nor was there a zygosity difference in the within-twinfamily effect of twin AUD ( $b=-.01,95 \%$ CI: $-0.17,0.15)$, suggesting that the factors responsible for the parent-offspring transmission were unrelated to genetic risk. The results of Model 6 indicated that there was a reduced but still statistically significant between-twin-families effect of AUD in a twin pair, even after controlling for demographic characteristics, other substance use, and other psychopathology in the twins and spouses $(b=.13,95 \%$ CI: $0.05,0.21)$.

Using AD diagnoses in parents. The pattern of results of the multilevel regression models that used AD diagnoses in the parents as predictors was similar to the models that used AUD symptom counts (see Table 6). An AD diagnosis in the twin or in the spouse was associated with increases of 0.29 (95\% CI: 0.11, 0.47) and 0.24 (95\% CI: $0.08,0.40)$ standard deviations, respectively, in AUD symptoms among the offspring (Model 2). The influence of maternal AD was slightly larger $(b=.31,95 \% \mathrm{CI}: 0.03,0.53)$ but 
Table 4

Mean Covariate-Adjusted Offspring Alcohol Use Disorder Symptom Counts by Twin Parent or Twin Pair History of Alcohol Dependence and Family Type

\begin{tabular}{|c|c|c|c|c|c|c|}
\hline \multirow[b]{2}{*}{ Row } & \multirow{2}{*}{$\begin{array}{l}\text { Alcohol dependence in twin } \\
\text { parent or twin pair }\end{array}$} & \multicolumn{5}{|c|}{ Offspring alcohol use disorder symptom count } \\
\hline & & $M$ & $95 \% \mathrm{CI}$ & $n$ Offspring & $n$ Twins & $n$ Twin pairs \\
\hline \multicolumn{7}{|c|}{ All twins } \\
\hline 1 & Twin parent unaffected & -0.03 & $-0.08,0.01$ & 2,116 & 1,102 & \\
\hline 2 & Twin parent affected & 0.25 & $0.09,0.42$ & 218 & 122 & \\
\hline \multicolumn{7}{|c|}{ Monozygotic twin pairs } \\
\hline 3 & Concordant-unaffected & -0.05 & $-0.12,0.02$ & 1,023 & & 348 \\
\hline 4 & Discordant-parent unaffected & 0.03 & $-0.25,0.31$ & 78 & & \\
\hline 5 & Discordant-parent affected & 0.21 & $-0.11,0.53$ & 55 & & 48 \\
\hline 6 & Concordant-affected & 0.41 & $-0.02,0.84$ & 36 & & 16 \\
\hline \multicolumn{7}{|c|}{ Dizygotic twin pairs } \\
\hline 7 & Concordant-unaffected & -0.05 & $-0.12,0.03$ & 878 & & 315 \\
\hline 8 & Discordant-parent unaffected & 0.17 & $-0.03,0.37$ & 138 & & \multirow{2}{*}{104} \\
\hline 9 & Discordant-parent affected & 0.23 & $0.02,0.45$ & 110 & & \\
\hline 10 & Concordant-affected & 0.44 & $-0.22,1.10$ & 17 & & 5 \\
\hline
\end{tabular}

Note. Covariates included were offspring age, age ${ }^{2}$, and sex, and co-parent (spouse) alcohol use disorder. Offspring symptom counts were transformed and standardized to a mean of zero and standard deviation of one. Means were weighted to produce estimates from the entire Australian Twin Registry cohort, and the confidence intervals reflect the clustered nature of the data. The boxes correspond to the discordant twin pairs in the tables. The two rows within each box correspond to either the affected or the unaffected twin from these discordant twin pairs. CI $=$ confidence interval.

not statistically different from paternal $\mathrm{AD}(b=.25,95 \% \mathrm{CI}: 0.11$, 0.38 ) in predicting offspring AUD. After controlling for demographic characteristics, other substance use, and other psychopathology in the twins and spouses, the influence of twin and spouse AD remained statistically significant (Model 3). Models 4-6 indicated that there were statistically significant, between-twinfamilies effects $(b=.45,95 \% \mathrm{CI}: 0.23,0.67)$ that remained significant even with the inclusion of covariates $(b=.33,95 \% \mathrm{CI}$ : $0.09,0.57)$, but there was no evidence of statistically significant within-twin-family effects among all of the offspring $(b=.10$, $95 \%$ CI: $-0.14,0.34)$ or among the offspring of MZ twin pairs $(b=.19,95 \%$ CI: $-0.22,0.60)$ and no evidence of a zygosity difference in the within-twin-family effect of twin AUD $(b=$ $-.13,95 \%$ CI: $-0.64,0.38)$.

\section{A Comparison of the Results With the Two Analytic Approaches}

The results of the between-families means comparisons and within-family multilevel regression modeling were consistent in failing to detect a statistically significant effect of parental AUD on offspring AUD symptoms after controlling for correlated familial factors, and in suggesting that this effect was modest at best. In the between-families analyses, the differences in standardized means ranged from -0.02 to 0.17 between the offspring of affected twins and those of the unaffected twins from discordant $\mathrm{MZ}$ twin pairs. In the within-family multilevel regression modeling, the differences between the offspring of twins from discordant MZ pairs were small and positive, with regression coefficients indicating that being the offspring of the twin with more AUD symptoms (when AUD symptom counts among the parents was used as the predictor) or the offspring of the affected twin in discordant pairs (when $\mathrm{AD}$ diagnoses among the parents was used as the predictor) was associated with increases in AUD symptoms in the offspring ranging from 0.07 to $0.19 S D$. In neither set of analyses was it possible to discern whether the correlated familial factors responsible for the association between offspring AUD and parental AUD were correlated genetic factors or correlated environments.

\section{Post Hoc Power Calculations}

With a focus on the size of parameter estimates and their associated confidence intervals, the issue of statistical power becomes less relevant. This is because even in the absence of statistical significance, an effect size and its confidence interval provides an important contribution to cumulative knowledge in psychology (Schmidt, 1996) and because once a study is conducted and the data are analyzed, "confidence intervals replace calculated power in describing results" (Wilkinson \& The Task Force on Statistical Inference, 1999, p. 596). Nonetheless, many readers expect to see a discussion of statistical power when statistically nonsignificant results are obtained. Post hoc power calculations may provide useful information for interpreting the results of this study and may provide a justification for why there was not more of a focus on parsing the correlated familial factors responsible for the association between offspring AUD and parental AUD into genetic and environmental components. Thus, we present approximate power for the between-families means comparisons based on published power tables (Cohen, 1988) and the power for the within-family multilevel regression modeling based on a series of simulations.

In the between-families means comparisons, there was inadequate power to detect the very small mean differences observed between the offspring of discordant-affected twins and discordant-unaffected twins in the combined sample of MZ and DZ discordant twin pairs (see footnote 7 ; power $\leq .20$ ) or among the offspring of affected twins versus unaffected twins from discordant MZ twin pairs (power $\leq .20$ ); there was respectable power to detect small effect sizes of .30 in the combined sample of the 
Table 5

Parameter Estimates of Multilevel Models Predicting Offspring Alcohol Use Disorder (AUD) Symptom Counts From AUD Symptom Counts in the Twin Parent or Twin Pair

\begin{tabular}{|c|c|c|c|c|c|c|c|c|c|c|c|c|}
\hline \multirow[b]{2}{*}{ Parameter } & \multicolumn{2}{|c|}{ Model 1} & \multicolumn{2}{|c|}{ Model 2} & \multicolumn{2}{|c|}{ Model 3} & \multicolumn{2}{|c|}{ Model 4} & \multicolumn{2}{|c|}{ Model 5} & \multicolumn{2}{|c|}{ Model 6} \\
\hline & $b$ & $S E$ & $b$ & $S E$ & $b$ & $S E$ & $b$ & $S E$ & $b$ & $S E$ & $b$ & $S E$ \\
\hline \multicolumn{13}{|c|}{ Random effects (variance components) } \\
\hline Twin family: Level 3 & $.07^{*}$ & .03 & $.06^{*}$ & .03 & $.06^{*}$ & .03 & $.06^{*}$ & .03 & $.06^{*}$ & .03 & $.06^{*}$ & .03 \\
\hline Nuclear family: Level 2 & $.21^{*}$ & .04 & $.20^{*}$ & .03 & $.19^{*}$ & .03 & $.20^{*}$ & .03 & $.20^{*}$ & .03 & $.19^{*}$ & .03 \\
\hline Offspring: Level 1 & $.60^{*}$ & .02 & $.54^{*}$ & .02 & $.54^{*}$ & .02 & $.54^{*}$ & .02 & $.54^{*}$ & .02 & $.54^{*}$ & .02 \\
\hline
\end{tabular}

Twin pair AUD

Parent AUD: Level 2

Between-twin families: Level 3

Within-twin families: Level 2

MZ within-twin families: Level 2

DZ-MZ within-twin families: Level 2

Spouse AUD: Level 2

Offspring covariates: Level 1

Sex

Age

$\mathrm{Age}^{2}$

Twin covariates: ${ }^{\mathrm{a}}$ Level 2

Cigarette use

History of conduct disorder symptoms

Spouse covariates: ${ }^{\mathrm{a}}$ Level 2

Age at first child
Fixed effects

\begin{tabular}{|c|c|c|c|c|c|c|c|c|c|}
\hline \multirow[t]{2}{*}{$.14^{*}$} & \multirow[t]{2}{*}{.02} & \multirow[t]{2}{*}{$.09^{*}$} & \multirow[t]{2}{*}{.03} & \multirow{2}{*}{$\begin{array}{l}.18^{*} \\
.06\end{array}$} & \multirow[b]{2}{*}{$\begin{array}{l}.03 \\
.04\end{array}$} & \multirow[b]{2}{*}{$.18^{*}$} & \multirow[b]{2}{*}{.03} & \multirow[b]{2}{*}{$.13^{*}$} & \multirow[b]{2}{*}{.04} \\
\hline & & & & & & & & & \\
\hline & & & & & & $\begin{array}{r}.07 \\
-.01\end{array}$ & $\begin{array}{l}.07 \\
08\end{array}$ & $\begin{array}{r}.05 \\
-.02\end{array}$ & $\begin{array}{l}.07 \\
08\end{array}$ \\
\hline $.14^{*}$ & .03 & $.14^{*}$ & .03 & $.14^{*}$ & .03 & $.14^{*}$ & .03 & $.14^{*}$ & .03 \\
\hline $.45^{*}$ & .04 & $.46^{*}$ & .04 & $.45^{*}$ & .04 & $.45^{*}$ & .04 & $.46^{*}$ & .04 \\
\hline $.20^{*}$ & .04 & $.20^{*}$ & .04 & $.20^{*}$ & .04 & $.20^{*}$ & .04 & $.20^{*}$ & .04 \\
\hline $.004^{*}$ & $<.001$ & $-.004^{*}$ & $<.001$ & $-.004^{*}$ & $<.001$ & $-.004^{*}$ & $<.001$ & $-.004^{*}$ & $<.001$ \\
\hline & & $.13^{*}$ & .05 & & & & & $.13^{*}$ & .05 \\
\hline & & $.08^{*}$ & .02 & & & & & $.08^{*}$ & .02 \\
\hline & & $-.01^{*}$ & .006 & & & & & $-.01^{*}$ & .006 \\
\hline
\end{tabular}

Note. Parameters are unstandardized. Parental and offspring symptom counts are distributed as $z$ scores. The parameters were weighted to produce estimates from the entire Australian Twin Registry cohort, and the standard errors reflect the clustered nature of the data. MZ = monozygotic; DZ = dizygotic.

${ }^{a}$ Only covariates with significant unique effects are shown; the covariates included for both twins and spouses were: educational attainment, age at the birth of their first child, frequency of church attendance, divorce, use of cigarettes, use of any illegal substances, conduct disorder symptoms, symptoms of major depression, suicidality. See Table 2 for an explanation of the models.

$* p<.05$

offspring of affected twins versus unaffected twins from discordant $\mathrm{MZ}$ and $\mathrm{DZ}$ twin pairs (power $\geq .74$ ), and there was inadequate power to detect effect sizes less than .30 among the offspring of affected twins versus unaffected twins from discordant MZ twin pairs (power $<0.47$ ). The power to detect a very small effect size of 0.13 between the offspring of unaffected MZ twins versus DZ twins from discordant pairs (an effect size consistent with a heritability of $52 \%$ ) was also inadequate (power $<0.35){ }^{8}$

In the within-family multilevel regression modeling with AUD symptom counts of the parents as predictors, the power was inadequate (power $=.16$ ) to detect the small effect observed in the present study but was respectable enough (power $=.72$ ) to detect a withintwin-family effect of $b=.15$ (still a modest effect). Given the within-twin-family effect observed in the present study $(b=.06)$, or an even larger within-twin-family effect of $b=.15$, the power was only .07 or .21 , to detect a statistically significant interaction between within-twin-family effect and twin zygosity. This interaction term provides a test of whether the familial confounds explaining the association between parental and offspring AUD are in part genetic (see Table 2). The power to parse the within-family confounds into genetic and environmental components was extremely low.

\section{Effect of Exposure to Parental Alcoholism}

In general community samples, many individuals with a history of AUD will represent transient, short-lived cases that remitted in early adulthood. The results of this study might be explained by the fact that some of the offspring of affected parents may not have been directly exposed to or may have had limited exposure to their parents' alcohol problems (Windle \& Tubman, 1999). The recency of AUD symptoms were not assessed in the twins but were assessed in the spouses. On the basis of the self-reports of symptom recency among the spouses with any AUD symptoms, we determined that $14 \%$ of the offspring were born after the last symptom occurrence and were thus never directly exposed to the alcohol problems in this particular parent. However, any possible

\footnotetext{
${ }^{8}$ The effect size used in the power calculation for detecting a genetic influence was based on an extension of a regression technique used to analyze twin data (DeFries \& Fulker, 1985). In standardized twin data, twice the difference between the means of MZ cotwins and DZ cotwins of affected probands provides an estimate of the heritability of a continuous trait. Similarly, in standardized CoT data, four times the difference between the means of nieces and nephews of MZ affected versus DZ affected aunts and uncles from discordant twin pairs provides an estimate of the heritability of a continuous trait. Power calculations were based on the heritability of the AUD symptom count among the twins in this sample (52\%; 95\% CI: $40 \%-56 \%$ ), which would translate into a standardized mean difference in the MZ and DZ offspring of discordant unaffected twins of .13 (i.e., .52/4). The very small mean difference expected with a moderately heritable trait highlights the low power of the CoT design for detecting genetic effects.
} 
Table 6

Parameter Estimates of Multilevel Models Predicting Offspring Alcohol Use Disorder (AUD) Symptom Counts From AD Diagnosis in the Twin Parent or Twin Pair

\begin{tabular}{|c|c|c|c|c|c|c|c|c|c|c|c|c|}
\hline \multirow[b]{2}{*}{ Parameter } & \multicolumn{2}{|c|}{ Model 1} & \multicolumn{2}{|c|}{ Model 2} & \multicolumn{2}{|c|}{ Model 3} & \multicolumn{2}{|c|}{ Model 4} & \multicolumn{2}{|c|}{ Model 5} & \multicolumn{2}{|c|}{ Model 6} \\
\hline & $b$ & $S E$ & $b$ & $S E$ & $b$ & $S E$ & $b$ & $S E$ & $b$ & $S E$ & $b$ & $S E$ \\
\hline \multicolumn{13}{|c|}{ Random effects (variance components) } \\
\hline Twin family: Level 3 & $.07^{*}$ & .03 & $.06^{*}$ & .03 & $.06^{*}$ & .03 & $.07^{*}$ & .03 & $.07^{*}$ & .03 & $.06^{*}$ & .03 \\
\hline Nuclear family: Level 2 & $.21^{*}$ & .04 & $22^{*}$ & .04 & $20^{*}$ & .03 & $.21^{*}$ & .04 & $.21^{*}$ & .04 & $20^{*}$ & .03 \\
\hline Offspring: Level 1 & $.60^{*}$ & .02 & $.54 *$ & .02 & $.54^{*}$ & .02 & $.54^{*}$ & .02 & $.54^{*}$ & .02 & $.54^{*}$ & .02 \\
\hline
\end{tabular}

Twin pair AD

Parent AUD: Level 2

Between-twin families: Level 3

Within-twin families: Level 2

MZ within-twin families: Level 2

DZ-MZ within-twin families: Level 2

Spouse AD: Level 2

Offspring covariates: ${ }^{\mathrm{a}}$ Level 1

Sex

Age

$\mathrm{Age}^{2}$

Twin covariates: ${ }^{\mathrm{a}}$ Level 2

Cigarette use

History of conduct disorder symptoms

Spouse covariates: ${ }^{\mathrm{a}}$ Level 2

Age at first child

Fixed effects

$\begin{array}{llll}.29^{*} & .09 & .17^{*} & .09\end{array}$

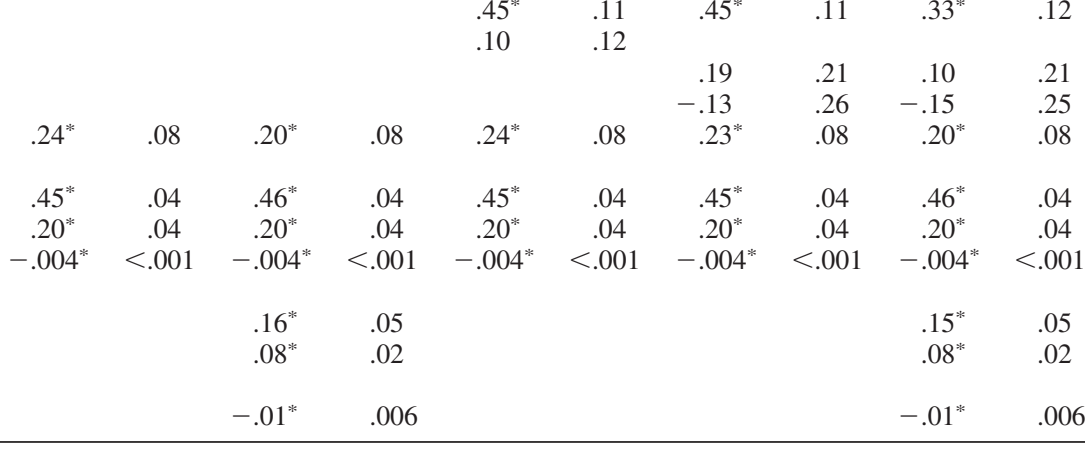

Note. Parameters are unstandardized. Offspring symptom counts are distributed as $z$ scores. The parameters were weighted to produce estimates from the entire Australian Twin Registry cohort, and the standard errors reflect the clustered nature of the data. AD = alcohol dependence; MZ = monozygotic; $\mathrm{DZ}=$ dizygotic.

${ }^{a}$ Only covariates with significant unique effects are shown; the covariates included for both twins and spouses were: educational attainment, age at the birth of their first child, frequency of church attendance, divorce, use of cigarettes, use of any illegal substances, conduct disorder symptoms, symptoms of major depression, and suicidality. See Table 2 for an explanation of the models.

$* p<.05$.

exposure or years of possible exposure to the alcohol problems of this parent from birth to age 18 years (based on spouse self-reports of symptom onsets and offsets) did not significantly predict offspring symptom counts over and above spouse AUD symptom counts or diagnoses of $\mathrm{AD}$.

\section{Discussion}

Among the 2,334 offspring of twins in this study, 556 (23.8\%) had a twin parent with a history of at least two AUD symptoms, and $218(9.3 \%)$ had a twin parent with a history of AD. The offspring who were the children of alcoholics had higher AUD symptom counts than did the offspring who were the children of nonalcoholics (effect sizes of .24 and .29 based on the broader and narrower definitions of alcoholism in the parents, respectively). These small differences in AUD symptom counts in the children of alcoholics versus the children of nonalcoholics can potentially be explained by the combined influence of two types of risk factors: (a) exposure to alcoholism in a parent, including characteristics of the childhood rearing environment provided by, and direct modeling of the drinking behavior of, the alcoholic parent and (b) familial risk factors that are associated with having an alcoholic birth parent, including susceptibility genes and environmental correlates, such as religious affiliation and socioeconomic status.
Studying the offspring of twins that are discordant for alcoholism allows one to unconfound these two sets of potential explanatory variables. The first set of risk factors would only pertain to the offspring of the affected twins, whereas the second set of risk factors would pertain to the offspring of both the affected twin and the unaffected twin. The most stringent control for correlated genetic factors comes from a comparison of the offspring of $\mathrm{MZ}$ twins discordant for alcoholism. Among the 212 offspring of MZ twins discordant for the broader definition of alcoholism and the 133 offspring of MZ twins discordant for the narrower definition of alcoholism, there was no longer a statistically significant difference between the children of alcoholics and the children of nonalcoholics (effect sizes of -.02 and .17). The results of this study suggest that if there is a potentially causal effect of being exposed to an alcoholic parent, it is modest at best.

Failure to detect a significant, direct environmental effect of exposure to parental alcoholism is consistent with the results of adoption studies (Cadoret et al., 1985, 1987; Cloninger et al., 1985; Goodwin et al., 1974; McGue, Sharma, \& Benson, 1996) and with a study of adult female twins and their parents (Kendler et al., 1994) but is inconsistent with the results of the only other CoT study of the intergenerational transmission of alcoholism (Jacob et al., 2003). The most likely explanation for this difference is in the disparate analytic approaches used in the two studies, in 
particular, the way that the data from the offspring of twin pairs who were concordant for alcoholism were handled. In the previous study, such offspring were combined together with offspring of twin pairs in which only the parent was affected and the additional information gained by taking into account the density of alcoholism in the twin pair was ignored. Thus, the outcomes in these offspring contributed to the direct effect of parental alcoholism, that is, to the potential causal effect. In the present study, the density of alcoholism in the twin pair was taken into account in the between-families means comparisons by treating the offspring of concordant affected twin pairs as a distinct group and was taken into account in the multilevel analyses by modeling the effect of having 0,1 , or 2 members of a twin pair affected with alcoholism (or modeling the mean AUD symptom count for the twin pair with continuous symptom counts among the parents as a predictor) as a between-twin-families effect, that is, a correlated familial effect. This correlated familial effect was a significant predictor of offspring AUD (regression coefficients associated with increases in AUD symptoms in the offspring ranging from .15 and .45 standard deviations), and was also a much stronger predictor than the within-family effect of exposure to an alcoholic parent. This correlated familial effect was not specific to the offspring of alcoholic parents but extended to the cousins of these offspring as well, even when the cousin's parent was unaffected. In other words, the nephews and nieces of alcoholics were also at increased risk for alcoholism.

Results from two of the Iowa adoption studies (Cadoret et al., 1985, 1987) suggest that this correlated familial effect may be due, at least in part, to nongenetic differences between families. In one study, the magnitude of the associations of adoptee AA and alcohol problems in the adoptive parents, siblings, and more distant relatives (uncles, aunts, and grandparents) were equal (odds ratios = 3.1; Cadoret et al., 1985), and in the other study, the magnitude of the associations between adoptee AA and alcohol problems in the adoptive parents (odds ratio $=2.7$ ) and in more distant relatives (odds ratio $=2.8$ ) were nearly equal (Cadoret et al., 1987). (Because of small sample sizes, none of these associations in the Iowa adoption studies were statistically significant.) Cadoret et al. $(1985 ; 1987)$ speculated that these similar associations might be due to a common environmental factor, such as commonly held family attitudes toward alcohol consumption or cultural factors associated with family ethnicity. By incorporating parents, offspring, uncles and aunts, and nieces and nephews, the CoT design offers a unique perspective on the effective family environment. The results of this study are consistent with the hypothesis of a common environmental factor that Cadoret et al. (1985; 1987) described over two decades ago, on the basis of the results obtained from studies of adoptive families. Although the cause of the associations are unambiguous in data obtained from adoptive families, it was not possible with these CoT data to disentangle the extent to which the correlated familial factors responsible for the association between offspring AUD and parental AUD were correlated environmental factors or correlated genetic factors.

\section{Characterizing the Familial Risk for Alcoholism}

Alcoholism researchers are increasingly recognizing the value of using a more fine-grained approach to characterizing the familial risk for alcoholism, rather than using a simple dichotomous classification based solely on a parent (Stoltenberg, Mudd, Blow, \& Hill, 1998; Windle, 1996). For example, based on alcoholism in the parents and grandparents, studies have categorized offspring as coming from unigenerational or multigenerational alcoholism pedigrees or (e.g., Finn \& Pihl, 1988), low-, medium-, or high-risk families (e.g., Barnow Schuckit, Smith, Preuss, \& Danko, 2002; Windle, 1996); have used continuous counts of the number of affected relatives (e.g., Schuckit, Smith, Pierson, Danko, \& Beltran, 2006); or have used weighted counts based on the degree of relatedness of the relative to the offspring (e.g., Zhou, King, \& Chassin, 2006). Other studies have also included the uncles and aunts of the offspring in determining the familial density of alcoholism (Hill \& Yuan, 1999; Hill et al., 2000). The benefits of this approach include the increased statistical power gained from a graded or continuous indicator of family history risk, and the identification of offspring at very high familial risk for alcoholism. Two results from the present study support this perspective. First, in all of the multilevel models, there was a significant additive (but not interactive) effect of twin and spouse alcoholism on offspring AUD symptoms. Offspring with both an alcoholic father and alcoholic mother had higher levels of AUD symptoms than did offspring with only one alcoholic parent. Second, the density of alcoholism in the twin pair significantly predicted AUD symptoms in the offspring. Typically, the goal of creating an index of the familial density of alcoholism is to identify offspring who are at especially high genetic risk for alcoholism; it is also likely that they are at especially high environmental risk for alcoholism as well.

\section{Effect of Level of Exposure to an Alcoholic Parent}

Unlike density of alcoholism in the nuclear and twin family, the level of exposure to an alcoholic parent was not related to offspring risk of developing AUD symptoms. Because of concerns that some of the offspring of alcoholic parents may never have been directly exposed to their parent's alcoholism, we identified instances in which the parent reported that their last AUD symptom offset occurred before the birth of the child (such information was only available for the spouses of the twins). The $14 \%$ of offspring who were born after their parent's recovery (similar to $24 \%$ obtained in another community-based study of children of alcoholics; DeLucia, Belz, \& Chassin, 2001) were not at significantly lower risk for developing AUD symptoms than were the offspring who were exposed to an alcoholic parent, and the number of years that the offspring could have been exposed to alcoholrelated problems in the parent was also not related to offspring AUD over and above the number of AUD symptoms or an AD diagnosis in the parent. In the Danish adoption study, there was also no systematic relation between the length of exposure to an alcoholic parent and AUD outcomes in the 30 sons who remained with their alcoholic birth parents (Goodwin et al., 1974), and in a community-based longitudinal study of children of alcoholics, there was no association between the recency of paternal AD symptoms (e.g., whether symptoms occurred in the past 3-5 years) and AUD diagnoses in offspring assessed in adolescence or in young adulthood (Chassin, Pitts, DeLucia, \& Todd, 1999). In a recent article presenting follow-up analyses of the data from the 
CoT study of Jacob et al. (2003), Duncan et al. (2006) reported that exposure to paternal alcoholism before age 13 years was not related to AUD outcomes in the offspring of fathers with a history of AD. These findings cast further doubt on the hypothesis that there is a direct environmental effect of having an alcoholic parent on offspring AUD outcomes.

\section{Sex-of-Parent Effects}

The inclusion of large numbers of both male and female twins and spouses allowed for an examination of sex-of-parent effects based on direct interviews with both parents and their offspring. There is continuing debate over whether the offspring of alcoholic mothers are at increased risk for alcoholism compared with the offspring of nonalcoholic mothers and whether the risk conferred by an alcoholic mother equals the risk conferred by an alcoholic father. The results of a meta-analysis of 32 studies of the families of alcoholics published between 1930 and 1982 suggested that there was a stronger influence of paternal than maternal alcoholism on the risk of alcoholism in offspring (Pollock, Schneider, Gabrielli, \& Goodwin, 1987). However, when only studies that included both fathers and mothers with alcoholism were examined, the influence of paternal and maternal alcoholism was nearly equal (McGue \& Slutske, 1996). Additional within-study evidence from a large population-based twin study in which both parents were directly interviewed about their history of alcoholism (Kendler et al., 1994) and from analyses of the family history reports from 5,877 participants in the National Comorbidity Survey (Kendler, Davis, \& Kessler, 1997) also suggested that the offspring of alcoholic mothers were as likely to develop alcoholism as the offspring of alcoholic fathers. More recently, a large, community-based longitudinal study (with either a combination of direct interview and family history reports or only family history reports) reported odds ratios of the associations between maternal AUD versus paternal AUD and offspring AD of 1.7 (nonsignificant) and 2.3 (significant), respectively (Lieb et al., 2002). Although the researchers concluded from this that paternal, but not maternal, AUD was related to AD in the offspring, it is not clear without conducting a formal test of the difference between these associations that an important sex-of-parent effect exists (the confidence intervals substantially overlapped). In the present study, there was no evidence for sex-of-parent effects; paternal versus maternal AUD (either AUD symptoms or AD diagnoses) conferred comparable risk for AUD symptoms in the offspring. Although there is disagreement in the literature, there appears to be stronger evidence to support the hypothesis that there are no sex-of-parent effects in the intergenerational transmission of alcoholism.

\section{Sex-of-Offspring Effects}

There is less controversy in the literature about whether there are sex-of-offspring effects in the intergenerational transmission of alcoholism. Along with a number of other studies (e.g., Chassin et al., 1999; Kendler et al., 1997; Lieb et al., 2002; Lynskey, Fergusson, \& Horwood, 1994), we found that parental AUD (either AUD symptoms or AD diagnoses) conferred the same risk for the development of AUD symptoms in male offspring as in female offspring (although Sher, Walitzer, Wood, \& Brent, 1991, obtained a stronger effect of paternal alcoholism for young women than for young men in a children-of-alcoholics study of college freshman). All of the studies are in agreement that both male and female children of alcoholic parents are at increased risk, compared with the children of nonalcoholic parents, for developing AUDs.

\section{Specificity of Effects}

The associations between parent and twin pair AUD and offspring AUD, although somewhat reduced, persisted even after indicators of externalizing and internalizing psychopathology and other substance use in the parents were taken into account. At least five more thorough investigations of the specificity of the effect of parental alcoholism on offspring AUD (and other outcomes) have been undertaken (Chassin et al., 1999; Hicks, Krueger, Iacono, McGue, \& Patrick, 2004; Kendler et al., 1997; Lynskey et al., 1994; Ohannessian et al, 2004). The results of three of these studies (Chassin et al., 1999; Kendler et al., 1997; Lynskey et al., 1994) are consistent with the present study in finding evidence of effects that are unique to parental alcoholism, whereas the other two studies (Hicks et al., 2004; Ohannessian et al, 2004) found that all of the risk associated with parental alcoholism could be explained by more general effects shared with other psychiatric and substance use disorders. Rather than conclude that the risk associated with parental AUD is either completely shared or completely specific, we concur with Kendler et al. (1997) that there are most likely risks that are common to other parental disorders as well as risks that are specifically associated with parental AUD.

\section{Lack of Evidence for Genetic Effects}

Although not a goal of this study, it is worth reflecting on reasons why there was no evidence for genetic influences in the intergenerational transmission of alcoholism in this CoT study. Similar results were also obtained in the previous CoT study of Jacob et al. (2003), who found that $11.7 \%$ and $11.1 \%$ of the 18-26-year-old offspring of MZ unaffected twins and DZ unaffected twins, respectively, from pairs discordant for $\mathrm{AD}$ had a lifetime history of AD. Adoption studies, on the other hand, have found evidence for genetic effects, at least among men (e.g., Cadoret et al., 1985, 1987; Cloninger, Bohman, \& Sigvardsson, 1981; Goodwin et al., 1973). One possible explanation for this discrepancy is that the biological parents in the adoption studies, who were identified from alcoholism treatment programs or official records, represent more severe cases of alcoholism than do those identified among the twins and spouses in the communitybased CoT studies. Thus, the offspring of alcoholics in the adoption studies would be at higher genetic risk for alcoholism, on average, than would the offspring of alcoholics in the CoT studies.

The results of this study also appear to conflict with the convincing evidence from community-based twin studies of the heritability of alcoholism (e.g., Heath et al., 1997; Prescott et al., 1999). The fact that genetic influences were not a significant contributor to the parent-offspring association in this CoT study but did substantially contribute to the variation in risk for AUD in twin studies may suggest that the risk factors for the development of AUD may not completely overlap across parental and offspring generations (cf. Kendler et al., 1994). Another contributor to differences in the results of the CoT studies and the twin studies 
is that the estimates of genetic influences obtained from the classic twin study also include genotype by shared environment interactions and genotype by environment correlations. To the extent that these are important contributors to variation in the risk for AUD, estimates of genetic influences obtained from twin studies may be larger than those obtained from other study designs.

The divergent findings in the CoT compared with the adoption and twin studies are probably due to differences in the statistical power for detecting genetic influences of the various study designs (Heath et al., 1985). The adoption and twin study are relatively powerful compared with the CoT study for detecting the effect of genetic influences. In parent-offspring adoption studies, genetic effects are inferred from comparing the similarity in biologically related versus non-biologically related parent-offspring dyads who share $50 \%$ and $0 \%$ of their genes, respectively. In twin studies, genetic effects are inferred from comparing the twin similarity in MZ dyads versus those in DZ dyads who share $100 \%$ and $50 \%$ of their genes, respectively. In the CoT study, one way that genetic effects are inferred is by comparing the offspring of unaffected twins from $\mathrm{MZ}$ discordant pairs to the offspring of unaffected twins from DZ discordant pairs, who share 50\% and $25 \%$ of their genes with their affected uncle or aunt, respectively. Comparisons from adoption and twin designs provide estimates of one half of the overall genetic effect, whereas comparisons from the CoT design provide an estimate of one fourth of the overall genetic effect. Thus, much larger sample sizes are required in the CoT study than in adoption and twin studies to detect a genetic effect.

\section{Limitations}

Several limitations of this study are worth noting. First, the statistical power was not adequate to detect as statistically significant the potential causal effect of parental AUD on offspring AUD symptoms, nor was power adequate to allow for a parsing of the familial confounds into genetic and environmental components. Given a larger sample size, it is likely that the modest causal effect of parental AUD that was observed would have reached statistical significance. Second, a relatively broad definition of alcoholism was used to characterize the parents in this study, and the parents were ascertained from a volunteer twin registry. The alcoholic parents in this CoT study may have underrepresented the extremes of alcohol-related pathology and environmental adversity or disadvantage, in which an important effect of exposure to parental alcoholism might have been detected. Third, AUDs in the parents and offspring were based on retrospective lifetime diagnoses. More reliable diagnoses obtained prospectively over the course of a longitudinal study would have provided greater resolution in identifying a potential causal effect of parental AUD.

\section{Implications}

The modest effect sizes obtained in this study suggest that only a minority of children of alcoholics develop alcohol-related problems as a consequence of their exposure to an alcoholic parent, an observation that has been noted by other researchers (e.g., Orford \& Velleman, 1990; Windle \& Tubman, 1999). One direction for research on children of alcoholics has been to identify those characteristics of parents and children that can explain this heter- ogeneity of outcomes (Orford \& Velleman, 1990; Windle \& Tubman, 1999). For example, although some children of alcoholics may model the drinking behavior of their alcoholic parent, there is also some evidence to suggest that others may respond to alcoholism in their family by limiting their drinking (e.g., Chassin \& Barrera, 1993; Hughes, Stewart, \& Barraclough, 1985; Orford \& Velleman, 1990), a phenomenon that Harburg, Davis, \& Caplan (1982) termed aversive transmission. Consistent with the aversive transmission hypothesis, Kendler et al. (1994) obtained a negative (albeit nonsignificant) estimate of vertical cultural transmission in a study of adult female twins and their parents.

Although the evidence from genetically informed studies is relatively consistent in failing to find a substantial association between exposure to an alcoholic parent and offspring AUD, this is based on only a handful of studies with relatively small sample sizes. For example, the genetically informed studies reviewed in the introduction of this article were based on the families of 58 alcoholic adoptive parents (Cloninger et al., 1985), 52 (Cadoret et al., 1985) and 21 (Cadoret et al., 1987) adoptive parents with any psychiatric problem (including alcohol-related problems), the families of 20 alcoholic parents with both adopted-away and non-adopted-away sons (Goodwin et al., 1974), and the families of $94 \mathrm{MZ}$ twin pairs discordant for alcoholism (Jacob et al., 2003). Altogether, including the number of families of $\mathrm{MZ}$ twin pairs discordant for alcoholism studied in this report, only 293 or 324 families have been the focus of genetically informed research on the environmental effect of parental alcoholism on offspring AUD.

Given the extraordinary number of children in this country who are exposed to AA and AD in the family (Grant, 2000), research that can disentangle the correlated genetic and environmental risk factors associated with such exposure is needed in the search to identify the active ingredients leading to the increased risk for the development of AUDs among the children of alcoholics. For example, because it has not yet been convincingly, empirically demonstrated that exposure to an alcoholic parent is an active ingredient leading to AUDs in the children of alcoholics, it is unclear whether prevention and intervention programs focused on modifying parents' behaviors will have the anticipated consequence of reducing AUDs among the offspring. It is hoped that insights gained from genetically informed research will eventually guide future prevention and intervention efforts because, as Moffitt (2005) has stated, "research that does not attack the co-occurrence of genetic and environmental risks will have only limited relevance for prevention" (p. 88).

\section{References}

Agrawal, A., Heath, A. C., Grant, J. D., Pergadia, M. L., Statham, D. J., Bucholz, K. K., et al. (2006). Assortative mating for cigarette smoking and for alcohol consumption in female Australian twins and their spouses. Behavior Genetics, 36, 553-566.

American Psychiatric Association. (1987). Diagnostic and statistical manual of mental disorders (3rd ed., rev.). Washington, DC: Author.

American Psychiatric Association. (1994). Diagnostic and statistical manual of mental disorders (4th ed.). Washington, DC: Author.

Barnow, S., Schuckit, M., Smith, T. L., Preuss, U., \& Danko, G. (2002). The relationship between the family density of alcoholism and externalizing symptoms among 146 children. Alcohol \& Alcoholism, 37, 383-387. 
Bucholz, K. K., Cadoret, R., Cloninger, C. R., Dinwiddie, S. H., Hesselbrock, V. M., Nurnberger, J. I., Jr., et al. (1994). A new semi-structured psychiatric interview for use in genetic linkage studies: A report on the reliability of the SSAGA. Journal of Studies on Alcohol, 55, 149-158.

Cadoret, R. J. (1986). Adoption studies: Historical and methodological critique. Psychiatric Developments, 1, 45-64.

Cadoret, R. J., O'Gorman, T. W., Troughton, E., \& Heywood, E. (1985). Alcoholism and antisocial personality: Interrelationships, genetic and environmental factors. Archives of General Psychiatry, 42, 161-167.

Cadoret, R. J., Troughton, E., \& O'Gorman, T. W. (1987). Genetic and environmental factors in alcohol abuse and antisocial personality. Journal of Studies on Alcohol, 48, 1-8.

Chassin, L., \& Barrera, M. (1993). Substance use escalation and substance use restraint among adolescent children of alcoholics. Psychology of Addictive Behaviors, 7, 3-20.

Chassin, L., Pitts, S. C., DeLucia, C., \& Todd, M. (1999). A longitudinal study of children of alcoholics: Predicting young adult substance use disorders, anxiety, and depression. Journal of Abnormal Psychology, $108,106-119$.

Cloninger, C. R., Bohman, M., \& Sigvardsson, S. (1981). Inheritance of alcohol abuse: Cross-fostering analysis of adopted men. Archives of General Psychiatry, 38, 861-868.

Cloninger, C. R., Bohman, M., Sigvardsson, S., \& von Knorring, A. (1985). Psychopathology in adopted-out children of alcoholics: The Stockholm Adoption Study. In M. Galanter (Ed.), Recent developments in alcoholism (Vol. 3, pp. 37-51). NY: Plenum Press.

Cohen, J. (1988). Statistical power analysis for the behavioral sciences (2nd ed.). Hillsdale, NJ: Erlbaum.

Cohen, J. (1994). The earth is round ( $p<.05)$. American Psychologist, 49, 997-1003.

DeFries, J. C., \& Fulker, D. W. (1985). Multiple regression analysis of twin data. Behavior Genetics, 15, 467-473.

DeLucia, C., Belz, A., \& Chassin, L. (2001). Do adolescent symptomatology and family environment vary over time with fluctuations in paternal alcohol impairment? Developmental Psychology, 37, 207-216.

D'Onofrio, B. M., Slutske, W. S., Turkheimer, E., Emery, R. E., Harden, K. P., Heath, et al. (2007). The intergenerational transmission of childhood conduct problems: A children of twins study. Archives of General Psychiatry, 64, 820-829.

D'Onofrio, B. M., Turkheimer, E., Emery, R. E., Slutske, W. S., Heath, A. C., Madden, P. A., \& Martin, N. G. (2005). A genetically informed study of marital instability and its association with offspring psychopathology. Journal of Abnormal Psychology, 114, 570-586.

Duncan, A. E., Scherrer, J. S., Fu, Q., Bucholz, K. K., Heath, A. C., True, W. R., et al. (2006). Exposure to paternal alcoholism does not predict development of alcohol-use disorders in offspring: Evidence from an offspring-of-twins study. Journal of Studies on Alcohol, 67, 649-656.

Ellis, D. A., Zucker, R. A., \& Fitzgerald, H. E. (1997). The role of family influences in development and risk. Alcohol Health \& Research World, 21, 218-226.

Finn, P. R., \& Pihl, R. O. (1988). Risk for alcoholism: A comparison between two different groups of sons of alcoholics on cardiovascular reactivity and sensitivity to alcohol. Alcoholism: Clinical and Experimental Research, 12, 742-747.

Goodwin, D. W., Schulsinger, F., Hermansen, L., Guze, S. B., \& Winokur, G. (1973). Alcohol problems in adoptees raised apart from alcoholic biological parents. Archives of General Psychiatry, 28, 238-243.

Goodwin, D. W., Schulsinger, F., Moller, N., Hermansen, L., Winokur, G., \& Guze, S. B. (1974). Drinking problems in adopted and nonadopted sons of alcoholics. Archives of General Psychiatry, 31, 164-169.

Gottesman, I. I., \& Bertelsen, A. (1989). Confirming unexpressed genotypes for schizophrenia. Archives of General Psychiatry, 46, 867-872.

Grant, B. F. (2000). Estimates of U.S. children exposed to alcohol abuse and dependence in the family. American Journal of Public Health, 90, $112-115$.

Harburg, E., Davis, D. R., \& Caplan, R. (1982). Parent and offspring alcohol use: Imitative and aversive transmission. Journal of Studies on Alcohol, 43, 497-516.

Harden, K. P., Lynch, S. K., Turkheimer, E., Emery, R. E., D'Onofrio, B. M., Slutske, W. S., et al. (2007). A behavior genetic investigation of adolescent motherhood and offspring mental health problems. Journal of Abnormal Psychology, 116, 667-683.

Harden, K. P., Turkheimer, E., Emery, R. E., D’Onofrio, B. M., Slutske, W., Heath, A., \& Martin, N. G. (2007). Marital conflict and conduct disorder in children of twins. Child Development, 78, 1-18.

Heath, A. C., Bucholz, K. K., Madden, P. A. F., Dinwiddie, S. H., Slutske, W. S., Bierut, L. J., et al. (1997). Genetic and environmental contributions to alcohol dependence risk in a national twin sample: Consistency of findings in women and men. Psychological Medicine, 27, 1381-1396.

Heath, A. C., Kendler, K. S., Eaves, L. J., \& Markell, D. (1985). The resolution of cultural and biological inheritance: Informativeness of different relationships. Behavior Genetics, 15, 439-465.

Heath, A. C., Madden, P. A., \& Martin, N. G. (1998). Assessing the effects of cooperation bias and attrition in behavioral genetic research using data weighting. Behavior Genetics, 28, 415-427.

Helzer, J. E., Bucholz, K. K., Bierut, L. J., Regier, D. A., Schuckit, M. A., \& Guth, S. E. (2006). Should DSM-IV include dimensional diagnostic criteria for alcohol use disorders? Alcoholism: Clinical and Experimental Research, 30, 303-310.

Hicks, B. M., Krueger, R. F., Iacono, W. G., McGue, M., \& Patrick, C. J. (2004). Family transmission and heritability of externalizing disorders: A twin-family study. Archives of General Psychiatry, 61, 922-928.

Hill, S. Y., Shen, S., Lowers, L., \& Locke, J. (2000). Factors predicting the onset of adolescent drinking in families at high risk for developing alcoholism. Biological Psychiatry, 48, 265-275.

Hill, S. Y., \& Yuan, H. (1999). Familial density of alcoholism and onset of adolescent drinking. Journal of Studies on Alcohol, 60, 7-17.

Hughes, J., Stewart, M., \& Barraclough, B. (1985). Why teetotallers abstain. British Journal of Psychiatry, 146, 204-208.

Jacob, T., \& Leonard, K. (1994). Family and peer influences in the development of adolescent alcohol abuse. In G. Boyd, J. Howard, and R. Zucker, (Eds.), The development of alcohol problems: Exploring the biopsychosocial matrix of risk (pp.123-155). Rockville, MD: National Institutes of Health.

Jacob, T., Waterman, B., Heath, A., True, W., Bucholz, K. K., Haber, R., et al. (2003). Genetic and environmental effects on offspring alcoholism: New insights using an offspring-of-twins design. Archives of General Psychiatry, 60, 1265-1272.

Kahler, C. W., \& Strong, D. R. (2006). A Rasch model analysis of DSM-IV alcohol abuse and dependence items in the National Epidemiological Survey on Alcohol and Related Conditions. Alcoholism: Clinical and Experimental Research, 30, 1165-1175.

Kendler, K. S., Davis, C. G., \& Kessler, R. C. (1997). The familial aggregation of common psychiatric and substance use disorders in the National Comorbidity Survey: A family history study. British Journal of Psychiatry, 170, 541-548.

Kendler, K. S., Neale, M. C., Heath, A. C., Kessler, R. C., \& Eaves, L. J. (1994). A twin-family study of alcoholism in women. American Journal of Psychiatry, 151, 707-715.

Kessler, R. C., Berglund, P., Demler, O., Jin, R., \& Walters, E. E. (2005). Lifetime prevalence and age-of-onset distributions of $D S M-I V$ disorders in the National Comorbidity Survey Replication. Archives of General Psychiatry, 62, 593-602.

Kline, R. B. (2004). Beyond significance testing: Reforming data analysis methods in behavioral research. Washington, DC: American Psychological Association.

Krueger, R. F., Nichol, P. E., Hicks, B. M., Markon, K. E., Patrick, C. J., 
Iacono, W. G., \& McGue, M. (2004). Using latent trait modeling to conceptualize an alcohol problems continuum. Psychological Assessment, 16, 107-119.

Lieb, R., Merikangas, K. R., Hofler, M., Pfister, H., Isensee, B., \& Wittchen, H.-U. (2002). Parental alcohol use disorders and alcohol use and disorders in offspring: A community study. Psychological Medicine, $32,63-78$.

Littel, R. C., Milliken, G. A., Stroup, W. W., Wolfinger, R. D., \& Schabenberger, O. (2006). SAS for mixed models (2nd ed.). Cary, NC: SAS Institute.

Little, R. J. A., \& Rubin, D. B. (1987). Statistical analysis with missing data. New York: Wiley.

Loftus, G. R. (1996). Psychology will be a much better science when we change the way that we analyze data. Current Directions in Psychological Science, 5, 161-171.

Lykken (1991). What's wrong with psychology anyway? In D. Cicchetti \& W. M. Grove (Eds.), Thinking clearly about psychology:, Vol. 1. Matters of public interest. Minneapolis, MN: University of Minnesota Press.

Lynch, S. K., Turkheimer, E., D’Onofrio, B. M., Mendle, J., Emery, R. E., Slutske, W. S., \& Martin, N. G. (2006). A genetically informed study of the association between harsh punishment and offspring behavior problems. Journal of Family Psychology, 20, 190-198.

Lynskey, M. T., Fergusson, D. M., \& Horwood, L. J. (1994). The effect of parental alcohol problems on rates of adolescent psychiatric disorders. Addiction, 89, 1277-1286.

Lynskey, M. T., Heath, A. C., Bucholz, K. K., Slutske, W. S., Madden, P. A. F., Nelson, E. C., et al. (2003). Escalation of illicit drug use in early onset cannabis users versus cotwin controls. Journal of the American Medical Association, 289, 427-433.

Maes, H. H. M., Neale, M. C., Kendler, K. S., Hewitt, J. K., Silberg, J. L., Foley, D. L., et al. (1998). Assortative mating for major psychiatric diagnoses in two population-based samples. Psychological Medicine, $28,1389-1401$.

McGue, M., Sharma, A., \& Benson, P. (1996). Parent and sibling influences on adolescent alcohol use and misuse: Evidence from a U.S. adoption cohort. Journal of Studies on Alcohol, 57, 8-18.

McGue, M., \& Slutske, W. (1996). The inheritance of alcoholism in women. In J. M. Howard, S. E. Martin, P. D. Mail, M. E. Hilton, \& E. D. Taylor (Eds.), Women and alcohol: Issues for prevention research. National Institute of Alcohol Abuse and Alcoholism. U.S. Department of Health and Human Services: Rockville, MD.

McLeod, J. D. (1993). Spouse concordance for alcohol dependence and heavy drinking: Evidence from a community sample. Alcoholism: Clinical and Experimental Research, 17, 1146-1155.

Moffitt, T. E. (2005). Genetic and environmental influences on antisocial behaviors: Evidence from behavioral-genetic research. Advances in Genetics, 55, 41-104.

Nance, W. E., \& Corey, L. A. (1976). Genetic models for the analysis of data from the families of identical twins. Genetics, 83, 811-826.

Ohannessian, C. M., Hesselbrock, V. M., Kramer, J., Kuperman, S., Bucholz, K. K., Schuckit, M. A., \& Nurnberger, J. I. (2004). The relationship between parental alcoholism and adolescent psychopathology: A systematic examination of parental comorbid psychopathology. Journal of Abnormal Child Psychology, 32, 519-533.

Orford, J., \& Velleman, R. (1990). Offspring of parents with drinking problems: Drinking and drug-taking as young adults. British Journal of Addiction, 85, 779-794.

Pollock, V. E., Schneider, L. S., Gabrielli, W. F., \& Goodwin, D. W. (1987). Sex of parent and offspring in the transmission of alcoholism: A meta-analysis. The Journal of Nervous and Mental Disease 175, 668-673.

Prescott, C. A., Aggen, S. H., \& Kendler, K. S. (1999). Sex differences in the sources of genetic liability to alcohol abuse and dependence in a population-based sample of U.S. twins. Alcoholism: Clinical and Experimental Research, 23, 1136-1144.

Raudenbush, S. W., \& Bryk, A. S. (2002). Hierarchical linear models: Applications and data analysis methods (2nd ed.). Thousand Oaks, CA: Sage.

Rice, J. P., Neuman, R. J., Saccone, N. L., Corbett, J., Rochberg, N., Hesselbrock, V., et al. (2003). Age and birth cohort effects on rates of alcohol dependence. Alcoholism: Clinical and Experimental Research, 27, 93-99.

Rutter, M., Pickles, A., Murray, R., \& Eaves, L. (2001). Testing hypotheses on specific environmental causal effects on behavior. Psychological Bulletin, 127, 291-324.

Schmidt, F. L. (1996). Statistical significance testing and cumulative knowledge in psychology: Implications for training of researchers. Psychological Methods, 1, 115-129.

Schuckit, M. A., Smith, T. L., Pierson, J., Danko, G. P., \& Beltran, I. A. (2006). Relationships among level of response to alcohol and the number of alcoholic relatives in predicting alcohol-related outcomes. Alcoholism: Clinical and Experimental Research, 30, 1308-1314.

Sher, K. J., Walitzer, K. S., Wood, P. K., \& Brent, E. E. (1991). Characteristics of children of alcoholics: Putative risk factors, substance use and abuse, and psychopathology. Journal of Abnormal Psychology, 100, $427-448$.

Singer, J. D. (1998). Using SAS PROC MIXED to fit multilevel models, hierarchical models, and individual growth models. Journal of Educational and Behavioral Statistics, 24, 323-355.

Slutske, W. S., Heath, A. C., Dinwiddie, S. H., Madden, P. A. F., Bucholz, K. K., Dunne, M. P., et al. (1997). Modeling genetic and environmental influences in the etiology of conduct disorder: A study of 2682 adult twin pairs. Journal of Abnormal Psychology, 106, 266-279.

Slutske, W. S., Heath, A. C., Dinwiddie, S. H., Madden, P. A. F., Bucholz, K. K., Dunne, M. P., et al. (1998). Common genetic risk factors for conduct disorder and alcohol dependence. Journal of Abnormal Psychology, 107, 363-374

Slutske, W. S., Hunt-Carter, E. E., Nabors-Oberg, R. E., Sher, K. J., Bucholz, K. K., Madden, P. A. F., et al. (2004). Do college students drink more than their non-college-attending peers? Evidence from a population-based longitudinal female twin study. Journal of Abnormal Psychology, 113, 530-540

Slutske, W. S., True, W. R., Scherrer, J. F., Goldberg, J., Bucholz, K. K., Heath, A. C., et al. (1998). Long-term reliability and validity of alcoholism diagnoses and symptoms in a large national telephone interview survey. Alcoholism: Clinical and Experimental Research, $22,583-588$

Statham, D. J., Heath, A. C., Bucholz, K. K., Bierut, L., Madden, P. A. F., Dinwiddie, S. H., et al. (1998). Suicidal behavior: An epidemiologic and genetic study. Psychological Medicine, 28, 839-855.

Stoltenberg, S. F., Mudd, S. A., Blow, F. C., \& Hill, E. M. (1998). Evaluating measures of family history of alcoholism: Density versus dichotomy. Addiction, 93, 1511-1520.

Stoolmiller, M. (1999). Implications of the restricted range of family environments for estimates of heritability and nonshared environment in behavior-genetic adoption studies. Psychological Bulletin, 125, 392-409.

True, W. R., Heath, A. C., Romeis, J. C., Bucholz, K., Slutske, W., Scherrer, J. F., et al. (1996). Models of treatment seeking for alcoholism: The role of genes and environment. Alcoholism: Clinical and Experimental Research, 20, 1577-1581.

Whitfield, J. B., Zhu, G., Heath, A. C., \& Martin, N. G. (2005). Choice of residential location: Chance, family influences, or genes? Twin Research and Human Genetics, 8, 22-26.

Wilkinson, L., \& The Task Force on Statistical Inference. (1999). Statistical methods in psychology journals: Guidelines and explanations. American Psychologist, 54, 594-604. 
Windle, M. (1996). On the discriminative validity of a family history of problem drinking index with a national sample of young adults. Journal of Studies on Alcohol, 57, 378-386.

Windle, M., \& Tubman, J. G. (1999). Children of alcoholics. In W. K. Silverman \& T. Ollendick (Eds.) Developmental issues in the clinical treatment of children and adolescents (pp. 393-414). Needham Heights, MA: Allyn \& Bacon.

Zhou, Q., King, K. M., \& Chassin, L. (2006). The roles of familial alcoholism and adolescent family harmony in young adults' substance dependence disorders: Mediated and moderated relations. Journal of Abnormal Psychology, 115, 320-331.

Received November 2, 2006 Revision received April 28, 2008 Accepted April 29, 2008

\section{ORDER FORM}

Start my 2008 subscription to the Journal of

Abnormal Psychology ISSN: 0021-843X

\section{— $\quad$ \$67.00, APA Member/Affiliate \\ \$146.00, INDIVIDUAL NoNMEMBER \\ $\$ 450.00$, INSTITUTION \\ In DC add $5.75 \%$ / In $M D$ add $6 \%$ sales tax}

Total Amount Enclosed

$\$$

Subscription orders must be prepaid. (Subscriptions are on a calendar year basis only.) Allow 4-6 weeks for delivery of the first issue. Call for international subscription rates.

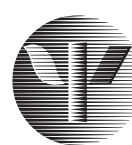

AMERICAN

PSYCHOLOGICAL ASSOCIATION

\section{SEND THIS ORDER FORM TO:}

American Psychological Association

Subscriptions

750 First Street, NE

Washington, DC 20002-4242

Or call 800-374-2721, fax 202-336-5568

TDD/TTY 202-336-6123.

For subscription information, e-mail:

subscriptions@apa.org
Check enclosed (make payable to APA)

Charge my: OVISA $\bigcirc$ MasterCard American Express

Cardholder Name

Card No. Exp. Date

\section{BILLING ADDRESS:}

Street

City

State Zip

Daytime Phone

E-mail

MAIL TO:

Name

Address

City State

Zip

APA Member \# ABNAOS 